\title{
On the escalation and de-escalation of conflict
}

\author{
Juan A. Lacomba \\ University of Granada, e-mail: jlacomba@ugr.es \\ Francisco Lagos \\ University of Granada, e-mail: fmlagos@ugr.es \\ Ernesto Reuben \\ IZA and Columbia University, e-mail: ereuben@columbia.edu \\ Frans van Winden
}

CEPR, Tinbergen Institute, and University of Amsterdam, e-mail: F.A.A.M.vanWinden@uva.nl

\begin{abstract}
We introduce three extensions of the Hirshleifer-Skaperdas conflict game to study experimentally the effects of post-conflict behavior and repeated interaction on the allocation of effort between production and appropriation. Without repeated interaction, destruction of resources by defeated players can lead to lower appropriative efforts and higher overall efficiency. With repeated interaction, appropriative efforts are considerably reduced because some groups manage to avoid fighting altogether, often after substantial initial conflict. To attain peace, players must first engage in costly signaling by making themselves vulnerable and by forgoing the possibility to appropriate the resources of defeated opponents.
\end{abstract}

This version: December 2013

Keywords: conflict; rent-seeking; appropriation; peace; escalation; tournaments; contests.

\footnotetext{
Acknowledgements: We gratefully acknowledge the helpful comments received from participants of seminars and conferences at Georgia State University, Maastricht University (IIPF), University of Jena (EPCSM), University of Innsbruck (EWEBE), George Mason University, University of Potsdam (ECPR), Bilkent University, University of Florence, Stockholm University, University of Munich (CESifo), and the Hebrew University of Jerusalem. A previous version of this paper was circulated under the title "After the war: An experimental study of postconflict behavior."

Note: This is the authors' version of a work that was accepted for publication in Games and Economic Behavior. Changes resulting from the publishing process may not be reflected in this document. A final version is published at http://dx.doi.org/10.1016/j.geb.2014.03.006.
} 


\section{Introduction}

Conflict, defined as a situation in which agents employ costly resources that are adversarially combined against one another (Garfinkel and Skaperdas, 2012), is a widespread social phenomenon with occasionally huge socio-economic consequences. A clear example is warfare. Other examples are political competition for dominance in public or private institutions, rentseeking by political interest groups, litigation by contending parties, and business contests in marketing or takeovers. At the heart of these examples is typically a choice between a productive and an appropriative use of resources as means of pursuing wealth. In their seminal studies Hirshleifer $(1988,1991 \mathrm{a})$ and Skaperdas (1992) model this choice as a contest between two players who allocate effort between production and "predation," with a higher predatory effort increasing the probability of appropriating the other player's production. ${ }^{1}$ In the meantime, this literature has branched into various directions, among other things dealing with dynamic issues (like economic growth) and the formation of alliances, and has become part of a more general theory of contests (Garfinkel and Skaperdas, 2007; Konrad, 2009). Next to theory, an empirical economic literature on conflict has developed. This literature includes, for example, Keynes (1920) classic critique on the reparations demanded from Germany after World War I, the assessment of the impact of military expenditures on economic growth Dunne and Uye (2010), and recent cost estimates of warfare such as Nordhaus (2002), Bilmes and Stiglitz (2008), and several studies in Hess (2008) and Garfinkel and Skaperdas (2012). In spite of their undeniable value, field empirical studies like these are handicapped by definitional issues (e.g., which non-monetary costs to include), severe difficulties in gathering data, and a lack of control to disentangle driving factors of conflict and to determine their impact (e.g., Sköns, 2006). In this respect, laboratory experimentation serves as an important complementary tool because it can focus on fundamental mechanisms through the control and opportunity to replicate that it offers. The experimental literature on conflict is recent and small (Abbink, 2012). For convenience, we will review this literature in the next section.

This paper presents an experimental study investigating the effects of post-conflict behavior and repeated interaction on behavioral factors fostering the escalation of conflict or the

\footnotetext{
${ }^{1}$ Garfinkel and Skaperdas (2012) review some earlier studies and refer to Haavelmo (1954) as the first one to model the basic choice between production and appropriation. Contest theory builds on the related rent-seeking model of Tullock (1980). The main differences between conflict models and rent-seeking models is that in the former the contested prize is endogenous and resources are locked into the contest (i.e., there is no safe haven, Neary, 1997a). These models are distinct from the literature on tournaments in that they focus on cases where there are no positive externalities for third parties, which exclude, for example, sportive contests.
} 
advancement of peace. Behavior in the aftermath of conflict is important for two reasons. First, its anticipation may influence the investment in conflict. For example, it may restrain conflict expenditures if the behavior of the defeated is expected to negatively affect the return on conflict. Second, in case of repeated interaction between the contestants, post-conflict behavior may be used for signaling purposes, affecting escalation or de-escalation of conflict and the possibility of peace.

We explore the importance of post-conflict behavior by changing the Hirshleifer-Skaperdas model in two notable ways. First, we realistically assume that appropriation of production after a contest is an act in itself instead of an automatic consequence of winning. This may be of importance, as experimental evidence suggests that agency matters, that is, people react differently to the same outcome depending on the intentions of the person behind it (e.g., Blount, 1995; Falk et al., 2008). Second, we include situations where the defeated party has the opportunity to increase the victor's appropriation costs by offering resistance or by applying scorched-earth tactics (Hirshleifer, 1991b). To some extent, the possibility that appropriation as such produces efficiency losses has been acknowledged in the literature by introducing an exogenous cost of predation (Grossman and Kim, 1995; Neary, 1997b; McBride and Skaperdas, 2009). In our setup, this cost is endogenous. More specifically, we investigate the following three extensions of the conflict game.

Total Conquest: In this extension, the winner of the contest gets to decide how much to appropriate of the loser's production (instead of automatically receiving all of it). This additional stage, which is formally equivalent to a dictator game, allows winners to restrain themselves. History shows that victors have treated their defeated very differently. However, in reality, many factors typically play a role and the underlying motives are hard to tease apart. Controlled experimental evidence on the dictator game suggests that people may show restraint in taking (Camerer, 2003). Therefore, some investment in conflict might be due to defensive reasons (i.e., protecting one's own production) or to a strong dislike of being defeated (e.g., because of betrayal aversion Bohnet et al., 2008) as opposed to the desire to appropriate someone else's production. Total Conquest also serves as a benchmark for our other extensions of the conflict game.

Resistance: Because appropriation generally takes time, there may be room for a response by the defeated. Often, the losing party of the contest may affect the ability of the victor to appropriate the capital, labor, or goods involved in production (e.g., Sköns, 2006). This can happen through capital or population flight, sabotage (e.g. destruction of oil fields or crops), strikes, lower work morale, or the redirection of effort to a shadow economy. All of 
these reactions will typically be costly to both parties. In this extension, we therefore assume an additional stage where the loser of the contest - knowing how much the winner wants to appropriate - can decide to destroy part or all of his own production. In this case, the winner can commit to a rate of appropriation but cannot avoid an economically destructive response by the defeated that hurts both. ${ }^{2}$

Scorched Earth: The underlying argumentation for this extension is similar to the previous one but we now assume that the winner of the contest cannot credibly commit ex ante, so that the loser must decide how much to destroy of his own production before knowing how much the winner will appropriate. ${ }^{3}$ For some dramatic military examples, one may think of the Kuwaiti oil fires started by the Iraqi military forces in 1990 when they were driven out by the U.S., or Hitler's order to destroy all of Germany's resources when he realized he had lost the war.

A second contribution of this paper is to study the differential impact of these three extensions of the conflict game on the dynamics of conflict and peace. As Garfinkel and Skaperdas (2007) conclude in their survey: "Very little is known about how to reduce, let alone eliminate, conflict." One obvious reason is that, typically, an unambiguously peaceful outcome does not exist. This holds for most rent-seeking experiments where, if there are no conflict expenditures, either no payoff is obtained or there is an equal probability of winning the contest. We give players the option to attain peace by simultaneously refraining from investing in conflict, which results in no appropriation by all. This peaceful outcome is particularly relevant and interesting when combined with repeated interaction in the various post-conflict settings. The reason being that these settings offer additional opportunities to signal peaceful intentionsfor example, by not appropriating as a victor in Total Conquest - that may be employed more often and be more effective than a unilateral reduction of conflict expenditures, which makes one vulnerable to the appropriative efforts of others.

We identify the differences between one-shot interaction and repeated play by comparing behavior when subjects are randomly re-matched after every iteration of the game (i.e., a Strangers matching protocol) to behavior when they always play the game with the same

\footnotetext{
${ }^{2}$ In our setting, the cost of resistance is destroyed income that would not be appropriated by the victor. In other words, our setting applies to situations where other potential costs of resistance, such as subsequent prosecution, are minimal (e.g., because individual actors are not identifiable) and where collective action problems are either resolved or not at play (e.g., when the oppressed can effectively communicate Cason and Mui, 2014).

${ }^{3}$ The difference in commitment between Scorched Earth and Total Conquest, has been studied by Van Huyck et al. (1995) with the peasant-dictator game and by Gehrig et al. (2007) with the ultimatum game. Their designs are different in various respects. Most notably, they miss the first conflict stage.
} 
counterpart (i.e., a Partners matching protocol). Depending on the type of conflict one is thinking of, one or the other form of interaction may be more relevant. For instance, warfare against different opponents in empire building is more like Strangers, while repeated political competition for dominance between the same parties is better captured by Partners. An example where both forms of interaction are important is cattle raids, which occur as single instances or as waves of raids by rival communities. This regularly happens, for instance, in South Sudan, where cows are extremely important. On one tragic occasion, in 2011, the Murle ethnic group and community killed 600 people from the Lou Nuer community, abducted 200 children, and stole around 25,000 cows, while an estimated 400 Murle were killed (Copnall, 2011). The raid was part of a cycle of vendettas stretching back for decades, and rumors had it that the next raid was already being prepared.

\section{Literature review}

The recognition of laboratory experiments as a useful tool for the analysis of conflict has generated a small but growing literature on this topic. Abbink (2012) provides a recent survey of laboratory experiments on conflict, while Dechenaux et al. (2012) reviews the experimental research on contests more generally, particularly Tullock contests, all-pay auctions, and rankorder tournaments (see also Öncüler and Croson, 2005; Herrmann and Orzen, 2008). Here we concentrate on the studies that are most closely related to ours.

Like us, Durham et al. (1998) base themselves on the model of Hirshleifer (1991a). Specifically, they examine whether changes in the technology of conflict affect productive activities and the manifestation of the "paradox of power" (i.e., poorer players improving their economic position relative to richer ones). They find broad support for the qualitative predictions of the model. We extend the work of Durham et al. (1998) by analyzing post-conflict behavior using the three extensions of Hirshleifer (1991a) described in the introduction.

A series of studies have looked at models that separate investments in defense from those in predation. Carter and Anderton (2001) conduct an experiment based on the predator-prey model of Grossman and Kim (1995) and find that increases in the relative effectiveness of predation against defense leads to behavioral changes in line with the theoretical prediction. ${ }^{4}$ Kovenock et al. (2010), Deck and Sheremeta (2012), and Chowdhury et al. (2011) examine variations of the Colonel Blotto game. They find that behavior is qualitatively in line with

\footnotetext{
${ }^{4}$ Two related studies that allow for differential investments in defense and predation are Duffy and Kim (2005) and Powell and Wilson (2008). The focus of these studies, however, is the emergence of productive societies from anarchic beginnings, and in the case of Duffy and Kim (2005), the role of the state in enabling this process.
} 
the theoretical predictions, but aggregate expenditures tend to exceed the predicted levels. Unlike these studies, we do not consider investments that are exclusively defensive. In our games, players can exhibit defensive behavior by investing in conflict, winning the contest, and then not appropriating the resources of the vanquished player. Hence, players with peaceful intentions face a commitment problem in the sense that successful defense is accompanied by the subsequent temptation to appropriate. In this respect, our study relates to the alliance game of Ke et al. (2013), where appropriation opportunities after victory make prior alliances harder to form.

There are plenty of experimental studies showing that cooperation tends to increase with both indefinitely and finitely repeated interaction (Andreoni and Croson, 2008). However, there is little evidence of such an effect in conflict games. ${ }^{5}$ Durham et al. (1998) do consider partners and strangers matching protocols and find little evidence that repeated interaction leads to sustained peaceful relations. As we discuss later, this might be due to the absence of a completely peaceful outcome and post-conflict opportunities where players can signal peaceful intentions. Moreover, unlike Durham et al. (1998), we analyze the dynamics leading to the escalation and de-escalation of conflict.

Our work is also related to Abbink and Herrmann (2009), Abbink and de Haan (2011), Abbink et al. (2012), and Bolle et al. (2014), who study the dynamics of destructive behavior in games where players (groups or individuals) have opportunities to hurt each other in repeated settings. They all find considerable evidence of destructive behavior. Bolle et al. (2014) also demonstrates how the escalation of this type of behavior is mediated by negative emotions. These studies, however, use settings without appropriation and, with the exception of Abbink et al. (2012), do not attempt to evaluate the impact of repeated interaction compared to a random-matching benchmark. ${ }^{6}$

Finally, a couple of studies analyze whether institutions such as the opportunity to make side payments (Kimbrough and Sheremeta, 2013) or political autonomy (Abbink and Brandts,

\footnotetext{
${ }^{5}$ McBride and Skaperdas (2009), Smith et al. (2011), and Tingley and Walter (2011) study situations diametric to ours. In these papers, future interaction weakens rivals and improves one's relative position in the future, giving players a clear incentive to invest more in present conflict when future interaction exists. In our paper, such an incentive does not exist and therefore it complements theirs in the sense that we study different conflict situations.

${ }^{6}$ Abbink et al. (2012) study the emergence of intergroup conflict in a game where two groups of subjects earn their endowment in a rent-seeking game and subsequently decide whether to destroy part of the endowment of the other group. Like us, they do not find significant a difference in destruction rates between partners and strangers matching. They do not report whether rent-seeking efforts differ between the two matching protocols.
} 
2009) facilitate the de-escalation of conflict. ${ }^{7}$ Kimbrough and Sheremeta (2013) show that both binding and non-binding side-payments significantly reduce the prevalence of conflicts. Abbink and Brandts (2009) demonstrate how costly struggle occurs because purely emotional elements impede players from agreeing on an acceptable level of autonomy.

\section{Total conquest}

In this section, we introduce and subsequently analyze the experimental results of our first extension of the Hirshleifer-Skaperdas conflict game.

\subsection{The game}

In the Total Conquest (TC) game, two players $i \in\{1,2\}$ interact in two distinct stages. Each player is endowed with $y$ points, which can be spent on conflict or used to generate income. In the first stage, each player $i$ simultaneously decides how many points $c_{i} \in[0, y]$ to spend on conflict. For simplicity, $i$ 's income equals the remaining $y-c_{i}$ points. If both players spend zero points on conflict, the game ends and each player receives a payoff equal to their endowment. However, if either player's conflict expenditures are positive, both players compete in a contest and play the second stage. The contest's winner is determined with a lottery in which each player's probability of winning equals their relative conflict expenditures, $p_{i}=c_{i} /\left(c_{i}+c_{j}\right)$. In the second stage, the winner of the contest decides how much of the loser's production to appropriate (the loser makes no decision). Specifically, if player $i$ wins, she chooses a "take rate" $t_{i} \in[0,1]$, which is the fraction of $y-c_{j}$ that she wishes to claim. In summary, if $c_{1}+c_{2}=0$ then each player earns $\pi_{1}=\pi_{2}=y$ points, else if $c_{1}+c_{2}>0$ then the expected earnings of each player $i \in\{1,2\}$ equal

$$
E\left[\pi_{i}\right]=\frac{c_{i}}{c_{i}+c_{j}^{e}}\left(y-c_{i}+t_{i}\left(y-c_{j}^{e}\right)\right)+\frac{c_{j}^{e}}{c_{i}+c_{j}^{e}}\left(1-t_{j}^{e}\right)\left(y-c_{i}\right),
$$

where $c_{j}^{e}$ and $t_{j}^{e}$ are $i$ 's expected value for $c_{j}$ and $t_{j}$. Note that the first element in the expression corresponds to $i$ 's expected earnings if she wins multiplied by her probability of winning, and the second element is $i$ 's expected earnings if she loses multiplied by her probability of losing.

As a benchmark, we calculate the optimal conflict expenditures of risk neutral players who maximize their monetary earnings in a one-shot TC game, which, using backward induction,

\footnotetext{
${ }^{7} \mathrm{~A}$ few studies evaluate the difficulties of rebuilding trust. Although these studies are not based on a conflict game, they show that a cooperative relation can be restored after a violation of trust. For example, by signaling trustworthiness with a combination of promises and cooperative actions (Schweitzer et al., 2006) or when facing competition from third parties (Reuben and Tyran, 2010; Lei et al., 2013).
} 
also apply if the game is finitely repeated. In Section 5, we discuss the consequences of relaxing these assumptions. The model is solved by backward induction. If player $i$ wins the contest, she will appropriate all of $j$ 's production, i.e. she chooses $t_{i}=1$. Therefore, labeling $c_{j}^{e}$ and $t_{j}^{e}$ as $i$ 's expected value for $c_{j}$ and $t_{j}$, if $i$ expects $j$ to choose $c_{j}^{e}>0$, we can obtain $i$ 's best reply by maximizing expression $(1)$, which gives: ${ }^{8}$

$$
c_{i}^{*}=\sqrt{c_{j}^{e}\left(\left(1+t_{j}^{e}\right) y-\left(1-t_{j}^{e}\right) c_{j}^{e}\right)}-c_{j}^{e},
$$

else if $i$ expects $j$ to choose $c_{j}^{e}=0$ then she simply has to spend the smallest possible amount $c_{i}^{*}=\epsilon$ in other to win the contest with certainty and take all of $j$ 's income. If we further assume that it is common knowledge that all players are risk neutral and maximize solely their monetary earnings, in the Nash equilibrium of the game both players spend half of their endowment on conflict, $c_{i}^{*}=c_{j}^{*}=\frac{1}{2} y$, and each player has an equal probability of winning $p_{i}^{*}=p_{j}^{*}=\frac{1}{2}$.

Compared to Durham et al. (1998) implementation of the Hirshleifer-Skaperdas model, our game differs in three important ways. First, appropriable resources are not part of a common pool. Therefore, although players can unilaterally engage in conflict to try to take complete control of the other's resources, they also have the option of avoiding each other by coordinating on the peaceful outcome. Second, investment in conflict determines only the probability of winning. Third, the winner decides what the final earnings are. ${ }^{9}$

\section{$3.2 \quad$ Experimental procedures}

We conducted a laboratory experiment in which subjects played twenty repetitions of the TC game (i.e., twenty periods). In ten of the twenty periods, subjects played under the Strangers matching protocol. The random rematching and lack of individual identifiers makes behavior in Strangers approximate behavior in a one-shot TC game. To investigate whether and how repeated interaction helps subjects avoid conflict, in the remaining ten periods, subjects played

\footnotetext{
${ }^{8}$ We assume that $i$ does not expect $j$ will condition $t_{j}$ on the value of $c_{i}$. If this were the case, $i$ would have to take into account how her conflict expenditures affects her earnings when she loses the contest.

${ }^{9}$ In order to check whether behavior is different in the TC game compared to the Hirshleifer-Skaperdas conflict game, we run two additional treatments. In one treatment, we exogenously set $t_{i}=t_{j}=1$ so that the winner is forced to take all of the loser's production. Comparing this treatment to the TC-game allows us to see whether endogenously selecting the take rate affects conflict expenditures. In the other treatment, we remove the lottery and set earnings equal to the share of conflict expenditures, as in Durham et al. (1998). Comparing the second treatment to the first allows us to test whether the lottery and the winner-takes-all nature of the contest affects conflict expenditures. In both treatments, conflict is avoided altogether when neither player spends points in it. We report the results of these treatments in Subsection 3.3.
} 
under the Partners matching protocol. Subjects were informed of the matching protocol just before they played the first of the respective ten periods. To control for sequence effects, half the subjects played the ten first periods as Partners and the second ten periods as Strangers whereas the other half played in the reverse order. In total, 76 subjects participated in the experiment. ${ }^{10}$ We used standard experimental procedures, including neutrally worded instructions, control questions, anonymity, and incentivized choices. The detailed procedures and instructions are available in the online supplementary materials or SM for short.

\subsection{Data analysis}

Throughout the paper, we use GLS regressions to test whether differences in conflict expenditures are statistically significant. Specifically, we run one regression with subject fixed effects to make within-subject comparisons (i.e., test the differences between Partners and Strangers) and two regressions with subject random effects (one for each matching protocol) to make between-subject comparisons (i.e., test differences between games) and test differences with respect to the theoretical benchmarks. In all regressions, we use robust standard errors clustered on sessions. The regressions are available in the SM. We also made basic treatment comparisons with non-parametric tests using session averages as units, which are also available in the online SM.

\section{TC-Strangers}

On average, subjects in TC-Strangers spend $0.631 y$ on conflict (other descriptive statistics are available in A). Notably, mean conflict expenditures are significantly higher than $0.500 y$ $(p \leq 0.001)$, which is the equilibrium if it is commonly known that all players are risk neutral and maximize solely their monetary earnings. ${ }^{11}$

If we look at the mean take rate, we can see that it is very close to complete appropriation (it equals 0.981 ). In fact, the modal take rate is the money-maximizing rate of 1 , which is

\footnotetext{
${ }^{10}$ In addition, 84 subjects participated in the additional treatments described in footnote 9 (40 in the first and 44 in the second). For these treatments, we used only Strangers matching.

${ }^{11}$ We find the following results for the treatments described in footnote 9 . If winners are forced to take all of losers' production, mean conflict expenditures equal 0.686y, which is higher than in TC-Strangers $(p=0.012)$. By contrast, if there is no lottery and earnings are proportional to expenditures, mean conflict expenditures equal $0.578 y$, which is somewhat lower than in TC-Strangers $(p=0.163)$. Hence, it appears that the endogenous selection of the take rate reduces conflict expenditures and the winner-takes-all nature of our game increases them. As Sheremeta et al. (2012), we find that a winner-takes-all lottery results in significantly higher conflict expenditures than the proportional allocation of earnings $(p=0.001)$.
} 
chosen 88.2 percent of the time. This is a remarkably high take rate compared to that in dictator games. For example, Forsythe et al. (1994) find that on average dictators take 77.3 percent of the available money and that only 30.4 percent take everything. A plausible reason behind the high take rates is that taking part in a conflict before making the allocation decision results in participants retaliating by taking more money. Alternatively, comparable take rates are seen when dictators earn the money they later divide. In this case, mean take rates equal 94.7 percent and 73.8 percent take everything (Cherry et al., 2002). Thus, it is possible that winning the contest has a similar effect as earning the money. Namely, it makes winners feel more entitled to the loser's earnings.

If we look at how conflict expenditures change over time, we find that they noticeably increase with repetition (see Figure 1). In period 1, conflict expenditures equal 0.520y. However, they consistently increase until they reach $0.715 y$ in period 10, which amounts to a sizable 36.9 percent increase (0.744 standard deviations). In fact, in period 10, 80.3 percent of the subjects spend more than $0.500 y$ on conflict, which is remarkable given that expression (2) indicates that risk neutral players who maximize solely their monetary earnings will not spend more than $0.500 y$ irrespective of the expected behavior of the other player. Throughout the paper, we test significant differences in time trends by calculating for each subject $i$ the slope obtained from regressing the variable of interest on the period number: $\beta_{i}$. Thereafter, we regress the resulting $\beta_{i}$ 's on treatment dummy variables to evaluate whether the distribution of $\beta_{i}$ 's differs significantly across treatments or whether its mean differs significantly from zero (we cluster standard errors on sessions). In addition to the $p$-value, we also report the mean value of $\beta_{i}$, which we denote as $\bar{\beta} .^{12}$ Using this procedure, we confirm that conflict expenditures significantly increase over time in TC-Strangers $(\bar{\beta}=0.019, p \leq 0.001) .{ }^{13}$ Thus, unlike in most rent-seeking experiments, where repetition moves play closer to the equilibrium implied by risk neutrality and own-earnings maximization (Herrmann and Orzen, 2008), in this case repetition leads subjects away from this theoretical benchmark.

In order to shed some light on why conflict escalates, we analyze how subjects adjust their conflict expenditures. Table 1 presents two GLS regressions that use subject $i$ 's change in

\footnotetext{
${ }^{12}$ This procedure is referred to as a two-stage random coefficient model (Davidian and Giltinan, 1995).

${ }^{13}$ The increasing time trend is pervasive: 50 subjects (65.8 percent) display an increasing time trend while only 17 subjects (22.4 percent) display a decreasing one. By contrast, in the treatments described in footnote 10 , the time trends in conflict expenditures are not significantly different from zero $(p \geq 0.791)-\bar{\beta}=0.001$ if winners are forced to take all of losers' production and $\bar{\beta}=-0.001$ if earnings are proportional to expenditures-and are significantly lower than in TC-Strangers $(p \leq 0.001)$. Hence, it appears choosing the take rate is an important component for conflict to escalate.
} 


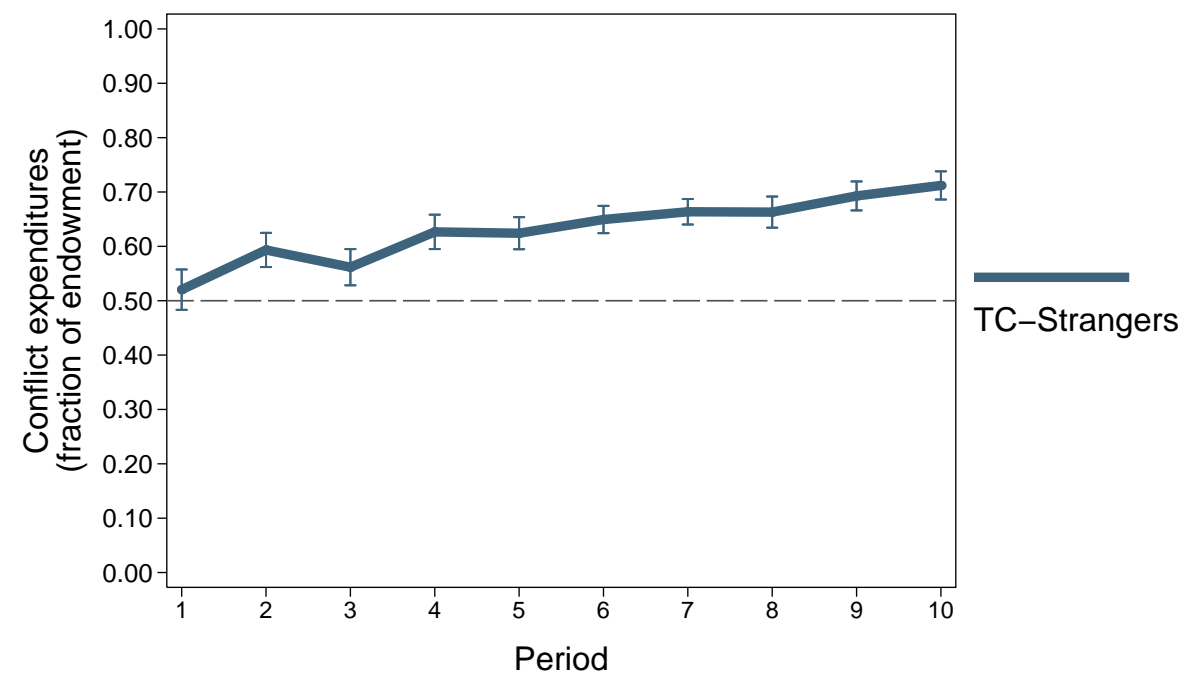

Figure 1: Mean conflict expenditures in TC-Strangers

Note: Mean fraction of the endowment spent on conflict. Error bars correspond to \pm one standard error.

conflict expenditures from period $x$ to period $x+1$ as the dependent variable. In the first regression (column A), we use four independent variables, labeled (i) to (iv). Variables (i) and (ii) allow us to see how subjects react to differences in the probability of winning, taking into account that they might react differently to positive and negative differences. Specifically, (i) equals the absolute difference between $i$ 's and $j$ 's probability of winning in period $x$, i.e. $\left|p_{i, x}-p_{j, x}\right|$, if $p_{i, x}>p_{j, x}$ and zero otherwise, and (ii) equals the same absolute difference in probabilities if $p_{i, x}<p_{j, x}$ and zero otherwise. Note that, given (i) and (ii), the reference state is subjects in pairs with equal probability of winning (which occurs 8.5 percent of the time). Variable (iii) is a dummy variable that equals one if $i$ lost the contest in period $x$, which allows us to see whether there is an effect of losing or winning irrespective of the probability of doing so. Lastly, as variable (iv), we control for the level of conflict expenditures by including $i$ 's conflict expenditures in period $x$, which we normalize by subtracting $i$ 's mean conflict expenditures over the ten periods, i.e. $c_{i, x}-\bar{c}_{i}$. In our second regression (column B), we add two independent variables that capture post-contest behavior: (v) equals the fraction of $j$ 's endowment that $i$ did not take, i.e. $\left(1-t_{i, x}\right)$ if $i$ won the contest in period $x$ and zero otherwise, and (vi) equals the fraction of $i$ 's endowment that $j$ did not take, i.e. $\left(1-t_{j, x}\right)$ if $j$ won the contest in period $x$ and zero otherwise. Both regressions have subject fixed effects and robust standard errors. ${ }^{14}$

We see that, ceteris paribus, subjects who had a lower probability of winning than their counterpart significantly increase their conflict expenditures $(p \leq 0.022)$. However, the reverse is not true: subjects who had a higher probability of winning do not significantly decrease

\footnotetext{
${ }^{14}$ We drop two observations from the one instance where both subjects spent zero points on conflict.
} 


\section{Table 1: Change in conflict expenditures in TC-Strangers}

Note: GLS regressions with $i$ 's change in conflict expenditures from periods $x$ to $x+1$ as the dependent variable and subject fixed effects. Standard errors are shown in parenthesis. Asterisks indicate significance at $1\left(^{* *}\right)$ and $5\left(^{*}\right)$ percent.

\begin{tabular}{lcccc}
\hline & \multicolumn{2}{c}{$(\mathrm{A})$} & \multicolumn{2}{c}{$(\mathrm{B})$} \\
Independent variables & coef. & s.e. & coef. & s.e. \\
\hline$(\mathrm{i})\left|p_{i, x}-p_{j, x}\right|$ if $p_{i, x}>p_{j, x}$ & 0.001 & $(0.044)$ & 0.005 & $(0.044)$ \\
$(\mathrm{ii})\left|p_{i, x}-p_{j, x}\right|$ if $p_{i, x}<p_{j, x}$ & $0.295^{*}$ & $(0.128)$ & $0.297^{*}$ & $(0.128)$ \\
(iii) $i$ lost & $0.035^{*}$ & $(0.016)$ & $0.036^{*}$ & $(0.017)$ \\
(iv) $c_{i, x}-\bar{c}_{i}$ & $-0.662^{* *}(0.125)$ & $-0.663^{* *}$ & $(0.125)$ \\
(v) $\left(1-t_{i, x}\right)$ if $i$ won & & & -0.082 & $(0.237)$ \\
(vi) $\left.\left(1-t_{(} j, x\right)\right)$ if $i$ lost & & & -0.197 & $(0.150)$ \\
Constant & -0.040 & $(0.031)$ & -0.039 & $(0.033)$ \\
\hline$R^{2}$ & 0.503 & 0.506 \\
no. of observations/subjects & $682 / 76$ & $682 / 76$ \\
\hline \hline
\end{tabular}

their conflict expenditures $(p>0.905)$. In addition, winning the contest per se has an effect. Namely, losers tend to increase their conflict expenditures compared to winners irrespective of the probability of winning. Moreover, the negative coefficient of (iv) shows that there is a tendency of individuals to regress to their mean contribution. Lastly, the post-contest variables do not seem to affect the change in conflict expenditures. Albeit, the lack of significance might be due to the small number of observations with a take rate lower than 1 . Overall, it seems that the main reason behind the escalation of conflict is the subjects' asymmetric reaction to differences in the probability of winning. ${ }^{15}$ Our first result summarizes these findings.

Result 1 (Escalation of Conflict) In TC-Strangers, subjects' initial conflict expenditures are similar to those predicted if it is commonly known that all players are risk neutral and maximize their own-earnings. However, the subjects' conflict expenditures steadily and significantly increase with repetition such that over ten periods the amount spent on conflict well-exceeds the amount predicted by this theoretical benchmark. This escalation is due to a sharp increase in conflict expenditures by subjects who face a lower probability of winning without an equivalent decrease in conflict expenditures by subjects who face a higher probability of winning.

\footnotetext{
${ }^{15}$ We also ran regressions using differences in conflict expenditures. The results are very similar but the $R^{2}$ of these regressions is lower. We also ran regressions including one-period lags of the independent variables. None of the lagged variables has a significant effect, and we cannot reject the hypothesis that the lagged variables are not jointly significant.
} 


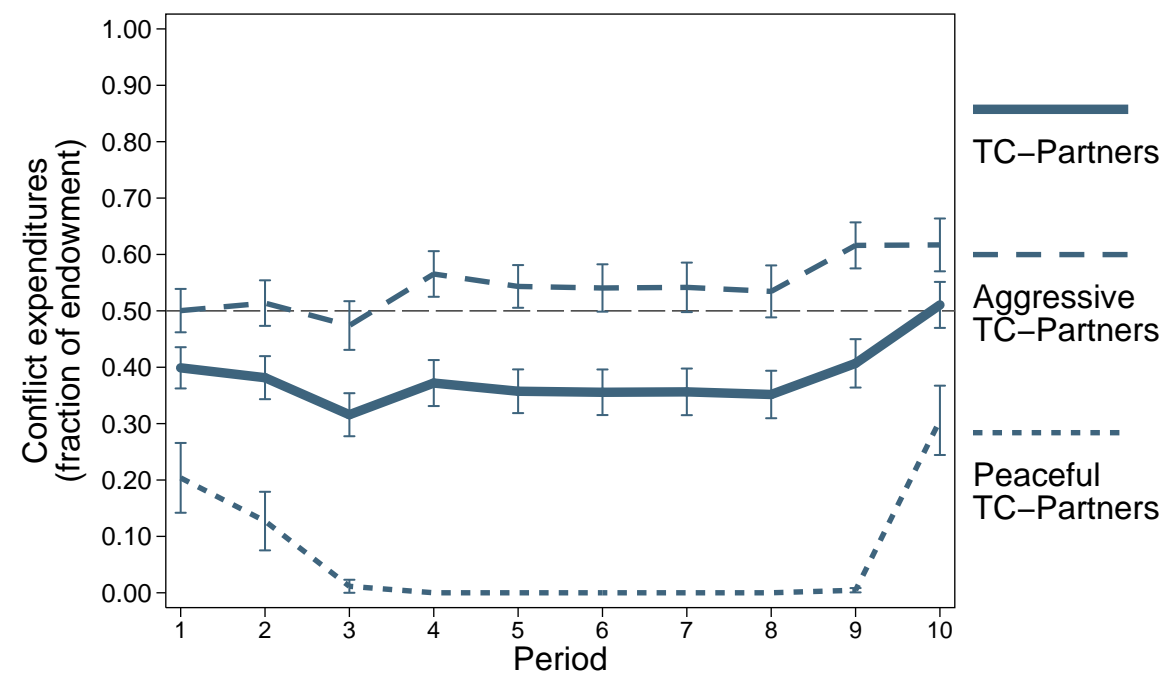

Figure 2: Mean conflict expenditures in TC-Partners

Note: Mean fraction of the endowment spent on conflict. Error bars correspond to \pm one standard error.

\section{TC-Partners}

In TC-Partners, mean conflict expenditures equal $0.381 y$, which is significantly lower than expenditures in TC-Strangers (39.6 percent lower, $p \leq 0.001$ ) and the 0.500y theoretical benchmark $(p=0.018)$. The mean take rate equals 0.811 , which is noticeably lower than in TC-strangers. ${ }^{16}$

Interestingly, the difference in conflict expenditures between Partners and Strangers is mostly due to the ability of the former to achieve peace: in 26.3 percent of all periods, subjects in TC-Partners simultaneously spend zero points on conflict (in TC-Strangers this fraction is only 0.3 percent). Moreover, peaceful outcomes are highly concentrated in a sizable minority of the groups: 25 out 38 groups (65.8 percent) did not attain a single peaceful outcome whereas the remaining 13 groups (34.2 percent) attained five or more (on average, 7.7 periods). We distinguish between these groups by referring to the former as aggressive groups and to the latter as peaceful groups. Given the stark differences in behavior, it is worthwhile to analyze aggressive and peaceful groups separately (descriptive statistics for aggressive and peaceful groups are available in A).

Remarkably, the conflict expenditures in aggressive groups are not that different from those in TC-Strangers (see Figure 2). On average, subjects in aggressive groups spend $0.545 y$ on conflict, which is only 13.6 percent less than TC-Strangers. Moreover, like in TC-Strangers, in

\footnotetext{
${ }^{16}$ Regressing take rates on a dummy variable indicating the matching protocol confirms that they are significantly lower in TC-Partners ( $p \leq 0.001$, GLS regression with subject fixed effects and standard errors clustered on sessions). See the SM for details.
} 
most periods mean conflict expenditures in aggressive groups exceed $0.500 y$ and increase with repetition. By contrast, conflict expenditures in peaceful groups are 89.7 percent less than in TC-Strangers (on average, 0.065y), are well below $0.500 y$, and decline sharply over periods such that all peaceful groups spend zero points on conflict from period 4 onwards, until an endgame effect in the last period. ${ }^{17}$

Next, we explore why some groups manage to reach a long-lasting peaceful relationship while others do not. Some of the groups are lucky enough to start a peaceful relationship in the first period ( 5 of the 13 peaceful groups). Thus, knowing ex ante that they will interact with the same opponent for some time already produces an important number of peaceful groups. Nevertheless, the majority of peaceful relationships are attained after a few periods in which conflict did occur.

To observe how groups de-escalate an initially conflicting interaction, we investigate which type of behaviors lead to peaceful relationships. Figure 3 summarizes our findings. It shows the fraction of times peace is attained in period $x+1$ given that there was a contest in period $x$ and conditioning on the subjects' behavior in that period. Since all peaceful relations were reached in the first five periods, we calculate these fractions for $x \leq 5$. Overall, a peaceful relationship is reached after a contest in only 0.057 of all periods. However, this fraction increases to 0.242 if one of the players spent zero points on conflict. In fact, this seems to be a necessary condition to attain peace as all peaceful relationships are preceded by a period in which one of the two players chose not to fight.

In addition, the behavior of the winner of the contest affects whether a peaceful relationship is attained. In particular, a peaceful relationship is more than seven times more likely if, after observing that the other player spent zero points on conflict, the winner chooses a low take rate (below the median) rather than a high take rate. A similar, albeit weaker, pattern is observed depending on the conflict expenditures of the winner: peace is almost twice as likely in periods following a winner whose conflict expenditures were below the median compared to periods following a winner whose conflict expenditures were above or equal to the median. We test whether these effects are statistically significant with a Probit regression. We find

\footnotetext{
${ }^{17}$ If we rerun previous regressions using a dummy variable to separate peaceful and aggressive groups we find that: conflict expenditures in peaceful groups are significantly lower than in aggressive groups $(p \leq 0.001)$ and groups in TC-Strangers $(p \leq 0.001)$. The time trend in conflict expenditures of peaceful groups is significantly different from that of aggressive groups $(\bar{\beta}=-0.020$ vs. $\bar{\beta}=0.011, p=0.002)$ and that of TC-Strangers $(p=0.002)$. To compare time trends, we omit the last period due to a clear endgame effect in peaceful groups. Although the difference in conflict expenditures is small, it is significantly lower in aggressive groups than in TC-Strangers $(p=0.004)$, but the time trend between the two is not significantly different $(p=0.967)$.
} 


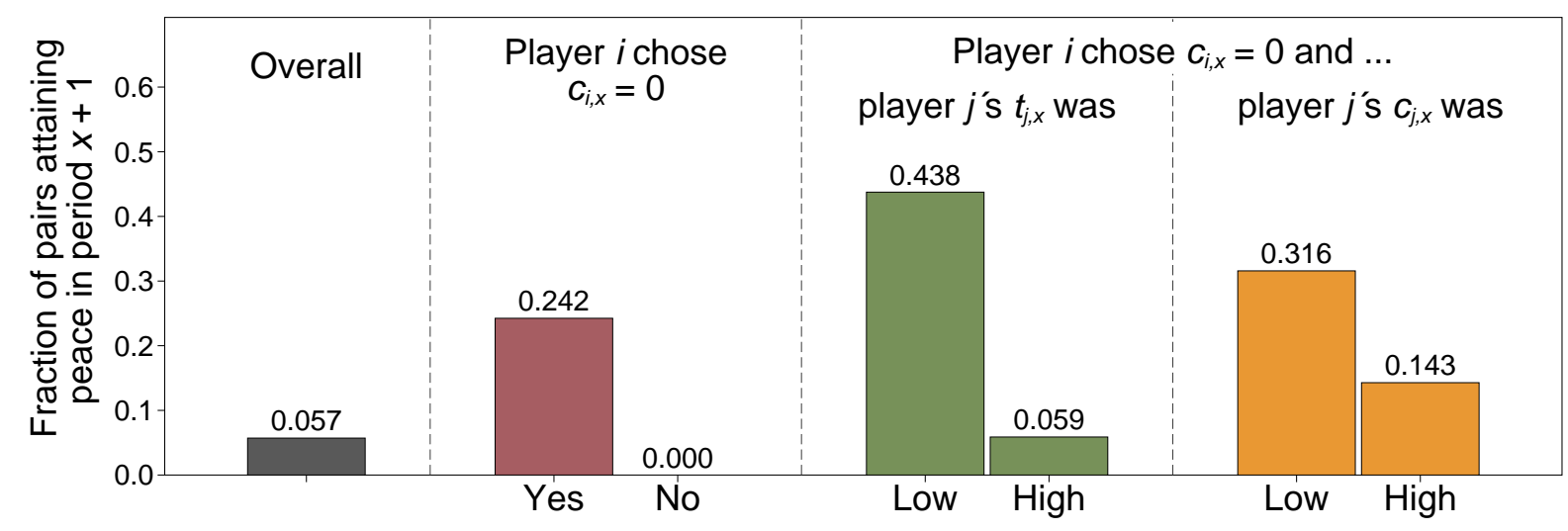

Figure 3: Fraction attaining peace depending on previous period behavior in TC-Partners

Note: Fractions are calculated based on the first five periods.

that a low take rate significantly increases the probability of attaining a peaceful relationship $(p=0.010)$ whereas winning with low conflict expenditures does not $(p=0.860) .{ }^{18}$ Our next result summarizes these findings.

Result 2 (De-escalation of Conflict) Conflict expenditures are considerably lower in TCPartners, where subjects are repeatedly interacting with the same counterpart. This difference is due to a sizable fraction of the groups avoiding conflict altogether and attaining a long-lasting peaceful relationship. Peace typically happens after periods of conflict if one subject cuts conflict expenditures to zero points and the other responds by choosing a low take rate.

\section{Scorched earth and resistance}

In this section, we extend the TC game by giving losers of the contest the opportunity to destroy their remaining resources. We do so with two different games: the Scorched Earth (SE) game and the Resistance (RE) game.

\footnotetext{
${ }^{18}$ We run Probit regressions with a dependent variable that equals one if a pair of subjects $i$ and $j$ achieve peace in period $x+1$ and zero otherwise. We look at cases in which $j$ does not spend points on conflict in period $x \leq 5$, which leaves us with 33 observations in 20 pairs of subjects. As independent variables we use dummy variables indicating (i) whether $i$ 's conflict expenditures were below the median, and (ii) whether $i$ 's take rate was below the median. The estimated regression equation is: Probability of peace in $x+1=-1.607(0.655)+$ $0.116(0.656) \times$ Low conflict expenditures $+1.362(0.526) \times$ Low take rate. Numbers in parenthesis correspond to robust standard errors clustered on pairs of subjects.
} 


\subsection{The games}

The SE and RE games have three stages. In the first stage of both games two players simultaneously decide how many points to spend on conflict. If both players spend zero points on conflict, the game ends and each player earns $\pi_{1}=\pi_{2}=y$ points. Otherwise, a contest takes place where the probability of winning is given by the players' relative conflict expenditures.

Like in the TC game, a winner $i$ chooses a take rate $t_{i} \in[0,1]$, which determines the fraction of loser $j$ 's remaining income that $i$ wishes to appropriate. However, unlike the TC game, in the SE and RE games, the loser of the contest also makes a decision. It consists of choosing the fraction of her income that she wishes to destroy. Specifically, $j$ selects a "destruction rate" $d_{j} \in[0,1]$, which is the fraction of $y-c_{j}$ that is destroyed and thus unavailable for $i$ to appropriate. In other words, $t_{i}$ applies only to the income not destroyed: $\left(1-d_{j}\right)\left(y-c_{j}\right)$. Therefore, in both the SE and RE games, if $c_{1}+c_{2}>0$ then the expected earnings of each player $i \in\{1,2\}$ are given by

$$
E\left[\pi_{i}\right]=\frac{c_{i}}{c_{i}+c_{j}^{e}}\left(y-c_{i}+t_{i}\left(1-d_{j}^{e}\right)\left(y-c_{j}^{e}\right)\right)+\frac{c_{j}^{e}}{c_{i}+c_{j}^{e}}\left(1-t_{j}^{e}\right)\left(1-d_{i}\right)\left(y-c_{i}\right),
$$

where $c_{j}^{e}, t_{j}^{e}$, and $d_{j}^{e}$ are $i$ 's expected value for $c_{j}, t_{j}$, and $d_{j}$. The first element of expression (3) corresponds to $i$ 's expected earnings if she wins multiplied by her probability of winning and the second to $i$ 's expected earnings if she loses multiplied by her probability of losing.

The difference between the SE and RE games is the sequence in which the winner and the loser make their decision. In the SE game, the loser first chooses a destruction rate, which is subsequently communicated to the winner, who then chooses a take rate. Conversely, in the $\mathrm{RE}$ game, the winner first chooses a take rate, which is subsequently communicated to the loser who then chooses a destruction rate. Therefore, the crucial difference between the two games is that in $\mathrm{RE}$ the loser can condition her destruction rate on the winner's take rate whereas in $\mathrm{SE}$ it is the winner who can condition her take rate on the loser's destruction rate.

Next, we calculate optimal conflict expenditures under the theoretical benchmark of risk neutral players who maximize their monetary earnings in a one-shot SE or RE game. Compared to the TC game, we need to introduce extra notation. Let's label $d_{j}^{e}$ as $i$ 's expected value for $d_{j}$. Moreover, let $t_{i}^{*}$ and $d_{i}^{*}$ denote the value of $t_{i}$ and $d_{i}$ that $i$ expects will maximize her earnings given the expected behavior of $j$. Note that $i$ always sets $t_{i}^{*}=1$ and $d_{i}^{*}=0$ as long as she expects $j$ to choose $d_{j}^{e}<1$ and $t_{j}^{e}<1$. If $i$ expects $t_{j}^{e}=1$ then she is left with no income and is therefore indifferent between any value $d_{i}^{*} \in[0,1]$, and similarly, if she expects $d_{j}^{e}=1$ then

she is left with nothing to take and is indifferent between any value $t_{i}^{*} \in[0,1]$. Regardless, if $i$ expects $j$ to choose $c_{j}^{e}>0$, we can obtain $i$ 's best reply by maximizing expression (3), which 
gives: ${ }^{19}$

$$
c_{i}^{*}=\sqrt{c_{j}^{e}\left(\left(t_{i}^{*}\left(1-d_{j}^{e}\right)+t_{j}^{e}+\left(1-t_{j}^{e}\right) d_{i}^{*}\right) y-\left(t_{i}^{*}\left(1-d_{j}^{e}\right)-t_{j}^{e}-\left(1-t_{j}^{e}\right) d_{i}^{*}\right) c_{j}^{e}\right)}-c_{j}^{e} .
$$

If $i$ expects $j$ to choose $c_{j}^{e}=0$ then as long as she expects $j$ will choose $d_{j}^{e}<1$ in some situations, she simply chooses $c_{i}^{*}=\epsilon$, wins the contest with certainty, and takes all of the income that $j$ does not destroy. On the other hand, if $i$ expects $c_{j}^{e}=0$ and for $j$ to always choose $d_{j}^{e}=1$ then, since there is nothing to gain from winning, her optimal response is to avoid the contest by choosing $c_{i}^{*}=0$. Note that expression (4) is increasing in $t_{j}^{e}$ and decreasing in $d_{j}^{e}$, which implies that $i$ will chose lower conflict expenditures the less $j$ takes or the more she destroys.

If we further assume that it is common knowledge that all players are risk neutral and maximize their monetary earnings, we get a straightforward prediction in the RE game. Using backward induction, one can see that once a winner $i$ and loser $j$ are determined, it is a subgameperfect Nash equilibrium for $i$ to choose $t_{i}^{*}=1$ and $j$ to choose $d_{j}^{*}=0 .{ }^{20}$ It follows that, in equilibrium, both players spend half their endowment in conflict $c_{i}^{*}=c_{j}^{*}=\frac{1}{2} y$. In the $\mathrm{SE}$ game, the optimal strategy of a winner $i$ is $t_{i}^{*}=1$ and therefore the loser $j$ is indifferent between any $d_{j}^{*} \in[0,1]$. If we assume that in equilibrium both players chose the same $d_{1}^{*}=d_{2}^{*}=d^{*}$ then for every $d^{*}<1$ there is an equilibrium where the optimal conflict expenditures are equal to $c_{i}^{*}=c_{j}^{*}=y\left(2-d^{*}\right)\left(4-d^{*}\right)$. If $d^{*}=1$, there are two equilibria: one where players spend $c_{i}^{*}=c_{j}^{*}=\frac{1}{3} y$ with the sole purpose of defending their income from appropriation (i.e., a selffulfilling equilibrium in which players spend resources on conflict simply because they expect the other will do so as well), and one where players choose $c_{i}^{*}=c_{j}^{*}=0$ and completely avoid the contest. However, note that if we introduce small perturbations in the actions of players, we do get a unique prediction in the SE game. Namely, as long as there is a small probability that the winner chooses $t_{i}^{*}<1$ then the loser's optimal choice is $d^{*}=0$ and the optimal conflict expenditures are once again $c_{i}^{*}=c_{j}^{*}=\frac{1}{2} y$.

In summary, we introduce two variants of the TC game to model situations where the loser of the contest gets the opportunity to destroy some or all of her remaining resources before the winner appropriates them. Introducing the possibility of destruction does not fundamentally change the equilibrium predictions.

\footnotetext{
${ }^{19}$ Once again, we are assuming that $i$ does not expect $j$ will condition $t_{j}$ and $d_{j}$ on the value of $c_{i}$.

${ }^{20}$ Note that although $j$ is indifferent between $d_{j}=0$ and any strictly positive destruction rate $d_{j}=\bar{d}>0$ when $t_{i}=1$, a positive destruction rate is not part of a subgame-perfect Nash equilibrium. The reason is that, if $d_{j}=0$ for $t_{i}<1$ and $d_{j}=\bar{d}$ for $t_{i}=1$ then $i$ 's optimal take rate is given by maximizing $y-c_{i}+t_{i}\left(y-c_{j}\right)$ with respect to $t_{i}$ subject to $t_{i}<1$, which does not have a solution.
} 


\subsection{Experimental procedures}

The experimental sessions for the $\mathrm{SE}$ and $\mathrm{RE}$ games were conducted in an identical way to those of the TC game, including the use of Strangers and Partners matching protocols. They are described in the SM. In total, 64 subjects played the SE game and 66 played the RE game.

\subsection{Data analysis}

\section{SE-Strangers and RE-Strangers}

Conflict expenditures are lower when losers have the option to destroy their income, particularly if they can condition their destruction on the take rate (for descriptive statistics, see A). On average, subjects spend $0.456 y$ in RE-Strangers, which is significantly lower than the $0.631 y$ spent in TC-Strangers $(p \leq 0.001)$ and the $0.573 y$ spent in SE-Strangers $(p \leq 0.001)$. The difference between TC-Strangers and SE-Strangers is not quite significant $(p=0.073)$. These differences in conflict expenditures are in line with a reduction in the profitability of winning the contest. For instance, in TC-Strangers the average winner gets 98.3 percent of the losers' remaining points. In SE-Strangers, the winners' winnings shrink to 62.7 percent, and in REStrangers, they are further reduced to a mere 46.0 percent.

A considerable number of subjects choose positive destruction rates in SE-Strangers. The mean destruction rate is 0.351 , which reflects the fact that losers destroy all their income 29.8 percent of the time. If the loser does not destroy, winners in SE-Strangers appropriate almost all of the losers' remaining income: the mean take rate is 0.929 , which is only 5.3 percent less than in TC-Strangers. In other words, in SE-Strangers, winners get a smaller percentage of the losers' income due to preemptive destruction by some of the losers.

Compared to the other treatments, take rates are noticeably lower in RE-Strangers: they average 0.645. As in SE-Strangers, losers in RE-Strangers are willing to choose positive destruction rates: the mean destruction rate is 0.249 and most destruction is due to losers destroying all their income 20.4 percent of the time. However, there is an important difference between these two games. Namely, in RE-Strangers losers can and do condition their destruction on the take rate chosen by the winner. For instance, the coefficient obtained by regressing destruction rates in TC-Partners on the observed take rate is $\beta=1.012$ and is significantly different from zero $(p \leq 0.001$, GLS regression with subject fixed effects and standard errors clustered on sessions). ${ }^{21}$ In other words, winners in RE-Strangers extract an even smaller fraction of the

\footnotetext{
${ }^{21}$ We do not find a relationship between take rates and destruction rates in SE-Strangers. The coefficient obtained by regressing the former on the latter is $\beta=-0.027$ ( $p=0.630$, GLS regression with subject fixed
} 


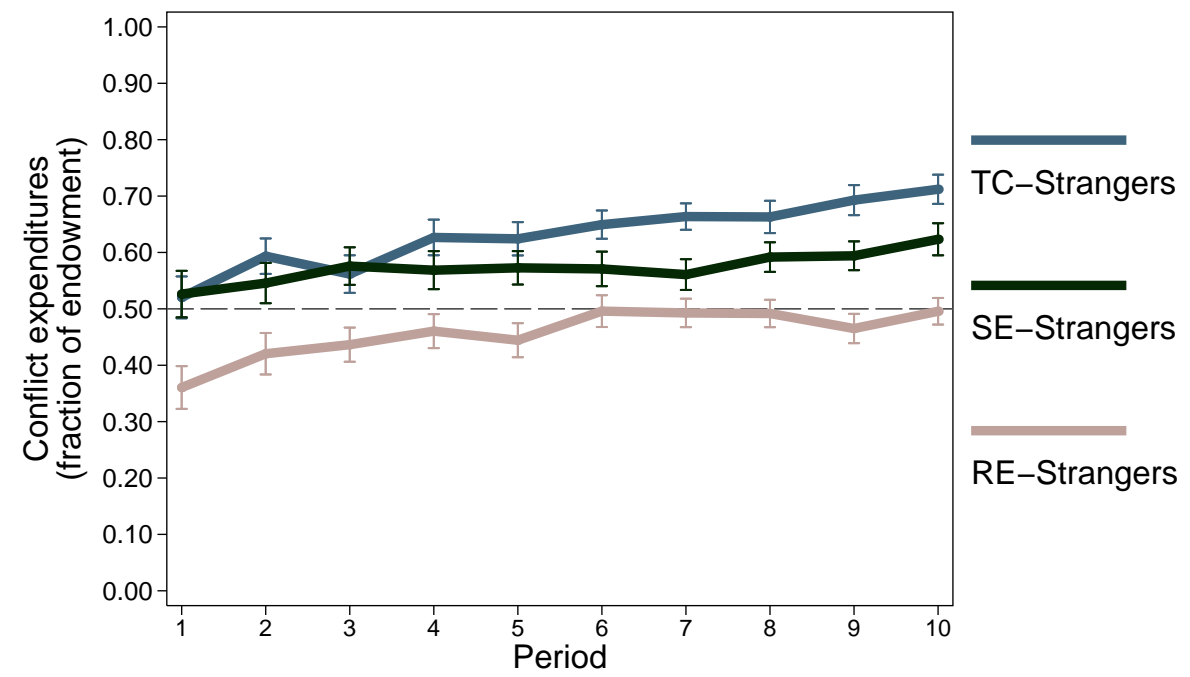

Figure 4: Mean conflict expenditures in TC-Strangers, SE-Strangers, and RE-Strangers

Note: Mean fraction of the endowment spent on conflict. Error bars correspond to \pm one standard error.

losers' income either because it is destroyed after they choose a high take rate or because they chose a low take rate in order to avoid destruction.

In other words, the destruction behavior of losers explains both the differences in take rates and the differences in conflict expenditures between the three games. In fact, if we take as given the destruction rate in SE-Strangers and we assume winners in RE-Strangers choose the take rate that maximizes their earnings given the observed behavior of losers (a take rate of 0.620, which implies an average destruction rate of 0.190), then, for conflict expenditures of $0.600 y$, expressions (2) and (4) predict that players will spend 6 percent less in SE-Strangers and 40 percent less in RE-Strangers compared to TC-Strangers, which is not far removed from the observed treatment differences (respectively, 9 percent and 28 percent). ${ }^{22}$

Importantly, although empowering the loser with the opportunity to destroy her income reduces overall conflict expenditures, this reduction translates into higher earnings only in REStrangers. As a fraction of their endowment, mean earnings equal 0.369 in TC-Strangers, 0.338 in SE-Strangers, and 0.467 in RE-Strangers. A GLS regression with subject random effects and standard errors clustered on sessions indicates that the difference in earnings between REStrangers and the other two treatments is statistically significant $(p \leq 0.017)$ but that between TC-Strangers and SE-Strangers is not ( $p=0.362$, see the SM for the regression's output).

effects and standard errors clustered on sessions).

${ }^{22}$ The losers' behavior and expressions (2) and (4) explain well the relative treatment differences in the conflict stage, but they fail to explain the levels of conflict expenditures, which should not to exceed $0.500 y$. 
Table 2: Change in conflict expenditures in SE-Strangers and RE-Strangers

Note: GLS regressions with $i$ 's change in conflict expenditures from periods $x$ to $x+1$ as the dependent variable and subject fixed effects. Standard errors are shown in parenthesis. Asterisks indicate significance at $1\left({ }^{* *}\right)$ and $5\left(^{*}\right)$ percent.

\begin{tabular}{|c|c|c|c|c|}
\hline \multirow[b]{2}{*}{ Independent variables } & \multicolumn{2}{|c|}{ SE-Strangers } & \multicolumn{2}{|c|}{ RE-Strangers } \\
\hline & coef. & s.e. & coef. & s.e. \\
\hline (i) $\left|p_{i, x}-p_{j, x}\right|$ if $p_{i, x}>p_{j, x}$ & -0.068 & $(0.036)$ & -0.024 & $(0.028)$ \\
\hline (ii) $\left|p_{i, x}-p_{j, x}\right|$ if $p_{i, x}<p_{j, x}$ & -0.001 & $(0.090)$ & $0.119^{* *}$ & $(0.046)$ \\
\hline (iii) $i$ lost & $0.072^{* *}$ & $(0.021)$ & -0.064 & $(0.051)$ \\
\hline (iv) $c_{i, x}-\bar{c}_{i}$ & $-0.830^{* *}$ & $(0.014)$ & $-0.719^{* *}$ & $(0.088)$ \\
\hline (v) $\left(1-t_{i, x}\right)$ if $i$ won & 0.070 & $(0.080)$ & $-0.190^{*}$ & $(0.096)$ \\
\hline (vi) $\left.\left(1-t_{(} j, x\right)\right)$ if $i$ lost & -0.018 & $(0.055)$ & -0.019 & $(0.069)$ \\
\hline (vii) $d_{j, x}$ if $i$ won & 0.024 & $(0.024)$ & -0.045 & $(0.033)$ \\
\hline (viii) $d_{i, x}$ if $i$ lost & -0.021 & $(0.022)$ & -0.038 & $(0.028)$ \\
\hline Constant & -0.017 & $(0.029)$ & 0.077 & $(0.040)$ \\
\hline$R^{2}$ & \multicolumn{2}{|c|}{0.483} & \multicolumn{2}{|c|}{0.464} \\
\hline no. of observations/subjects & \multicolumn{2}{|c|}{$572 / 64$} & \multicolumn{2}{|c|}{$594 / 66$} \\
\hline
\end{tabular}

Like in TC-Strangers, we observe increasing conflict expenditures over time in both in SEStrangers and RE-Strangers (see Figure 4). In SE-Strangers, conflict expenditures increase 18.5 percent over the ten periods (0.386 standard deviations), and in RE-Strangers they increase 37.5 percent (0.557 standard deviations). We do not find that the time trend in conflict expenditures of TC-Strangers differs significantly from that of SE-Strangers or RE-Strangers $(\bar{\beta}=0.077$ and $\bar{\beta}=0.118 ; p=0.054$ and $p=0.358)$. We also find similar effects across treatments if we look at how subjects adjust their conflict expenditures from one period to the next. Specifically, we run regressions for SE-Strangers and RE-Strangers with the same specification as the second regression in Table 1, but we include two additional independent variables: (vii) the destruction rate chosen by $j$, i.e. $d_{j, x}$ if $i$ won the contest in period $x$, and (viii) the destruction rate chosen by $i$, i.e. $d_{i, x}$ if $j$ won the contest in period $x$. We present the estimated coefficients in Table 2 .

Like in TC-Strangers, in RE-Strangers, subjects who had a lower probability of winning significantly increase their conflict expenditures $(p=0.009)$ while those who had a higher probability of winning do not significantly decrease their conflict expenditures $(p=0.397)$, which explains why there is an upward trend in conflict expenditures. However, unlike in TCStrangers, we do not find that winning or losing the contest influences the subjects' behavior 
in RE-Strangers. In SE-Strangers, we see the opposite pattern. Namely, we do not find that subjects react significantly to differences in the probabilities of winning ( $p>0.057)$, but we do see that, irrespective of differences in the probability of winning, losers significantly increase their conflict expenditures compared to winners $(p=0.001)$. In SE-Strangers, this effect is quite pronounced and is the driving force behind the overall increase in conflict expenditures. By and large, post-contest actions do not influence the adjustment of conflict expenditures in either SE-Strangers or RE-Strangers. ${ }^{23}$ Our third result summarizes these findings.

Result 3 (Destruction and the Escalation of Conflict) Compared to TC-Strangers, overall conflict expenditures are lower if losers have the opportunity to destroy their income before it is appropriated. The decrease in conflict expenditures is explained by the loser's destruction behavior, which reduces the incentive to win the contest. The option to destroy, however, does not change the escalation of conflict expenditures over time.

\section{SE-Partners and RE-Partners}

The introduction of repeated interaction significantly decreases conflict expenditures in the $\mathrm{SE}$ and RE games. Compared to Strangers, mean conflict expenditures decrease to 0.371y in SE-Partners (35.3 percent less, $p=0.005$ ) and to $0.278 y$ in RE-Partners (39.1 percent less, $p \leq 0.001) .{ }^{24}$ Moreover, just like for the TC game, the difference in conflict expenditures between Partners and Strangers is due to some groups consistently attaining five or more periods of peace - 10 groups in SE-Partners (31.3 percent) and 14 groups in RE-Partners (42.4 percent) - accounting for more than 87.5 percent of all the peaceful periods. ${ }^{25}$ Once again, we refer to these groups as peaceful groups and to the rest as aggressive groups (for descriptive statistics, see A).

As in the TC game, behavior in aggressive groups in SE-Partners and RE-Partners is similar to that in SE-Strangers and RE-Strangers (see Figure 5). First, compared to Strangers, mean conflict expenditures in aggressive groups are only 11.0 percent less in the SE game and 3.5 percent less in the RE game. Second, conflict expenditures increase with repetition in both

\footnotetext{
${ }^{23}$ The only exception occurs in RE-Strangers where subjects significantly decrease their conflict expenditures if they win the contest and then choose a low take rate $(p=0.048)$.

${ }^{24}$ Interestingly, repeated interaction seems to reduce the differences in conflict expenditures between the games. Conflict expenditures are still lowest in the RE game and highest in the TC game, but there are no longer any statistically significant differences between the three treatments $(p>0.059)$. The comparative statics for take and destruction rates are very similar between Partners and Strangers in the three games.

${ }^{25}$ The frequency of peaceful groups does not differ significantly across games ( $\chi^{2}$ test, $p=0.619$ ).
} 


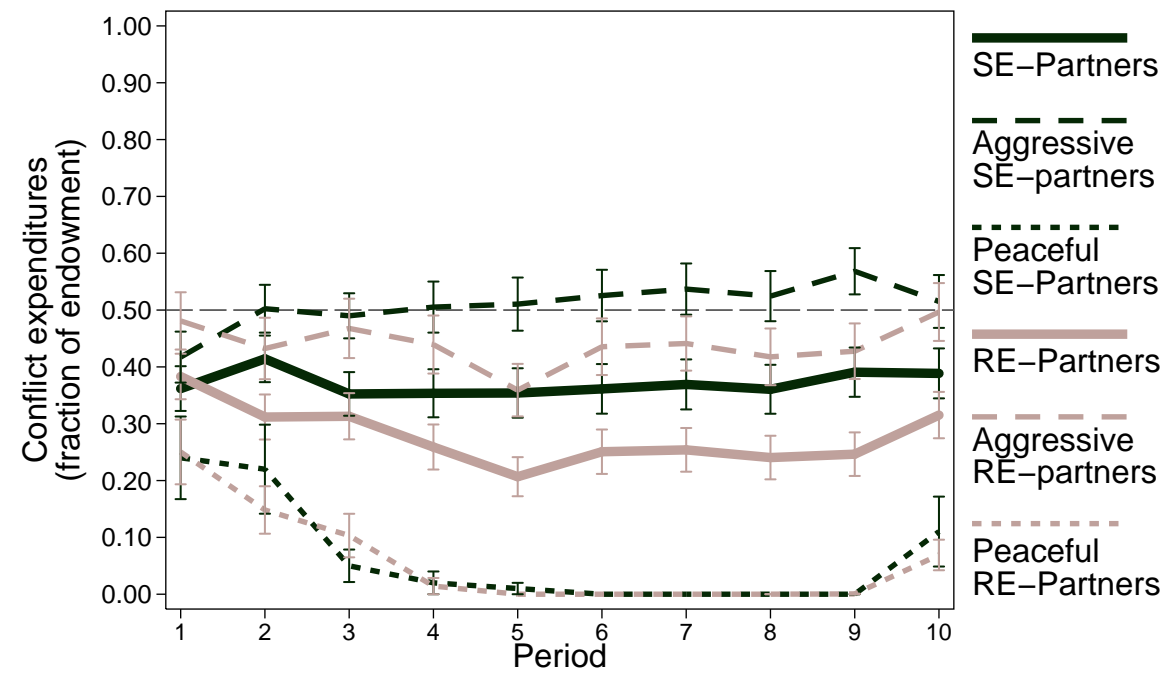

Figure 5: Mean conflict expenditures in SE-Partners and RE-Partners

Note: Mean fraction of the endowment spent on conflict. Error bars correspond to \pm one standard error.

cases. By contrast, mean conflict expenditures in peaceful groups in SE-Partners and REPartners are at least 87.0 percent less than those in Strangers, and they decline over time until the endgame effect in the last period. ${ }^{26}$

Many of our findings concerning peaceful groups in TC-Partners carry through to the SE and RE games. ${ }^{27}$ This can be seen in Figure 6, which shows the fraction of times peace is attained in period $x+1$ conditioning on the subjects' behavior in period $x \leq 5$. Like in TC-Partners, all peaceful relationships are preceded by a period in which one player spends zero points on conflict, which reinforces the notion that this behavior is necessary to attain peace. In addition, the conflict expenditures of the winner in period $x$ affect whether a peaceful relationship is attained in period $x+1$. Specifically, peace is twice as likely in SE-Partners and almost three times as likely in RE-Partners when the winner's conflict expenditures are below the median compared to cases where they are above or equal to the median. We also find that,

\footnotetext{
${ }^{26}$ Once again, if we rerun previous regressions using a dummy variable to separate peaceful and aggressive groups we find that: in both the SE and RE games, conflict expenditures are significantly lower in peaceful groups compared to aggressive groups $(p \leq 0.001)$ and to groups in Strangers $(p \leq 0.001)$. Moreover, peaceful groups exhibit a significantly different time trend in conflict expenditures compared to aggressive groups $(p \leq 0.001)$ and to subjects in Strangers $(p \leq 0.015)$. Once again, when comparing time trends we exclude the last period due to the endgame effect in peaceful groups. Finally, compared to Strangers, aggressive groups display lower conflict expenditures $(p=0.001)$ and no difference in the time trend $(p=0.438)$ in the SE game, and no difference in conflict expenditures $(p=0.160)$ and a smaller time trend $(p=0.022)$ in the RE game.

${ }^{27}$ As in TC-Partners, although some groups start a peaceful relationship from the first period (3 out 10 peaceful groups in SE-Partners and 2 out of 14 in RE-Partners), most peaceful relationships are reached after some conflict.
} 
(a) Scorched Earth

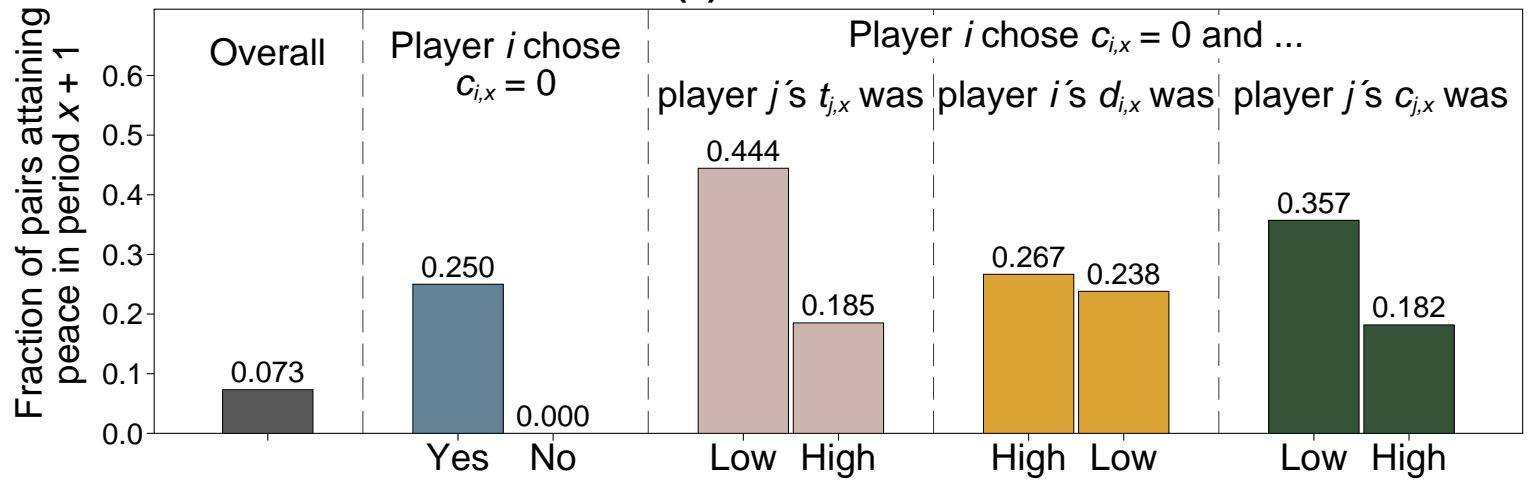

(b) Resistance

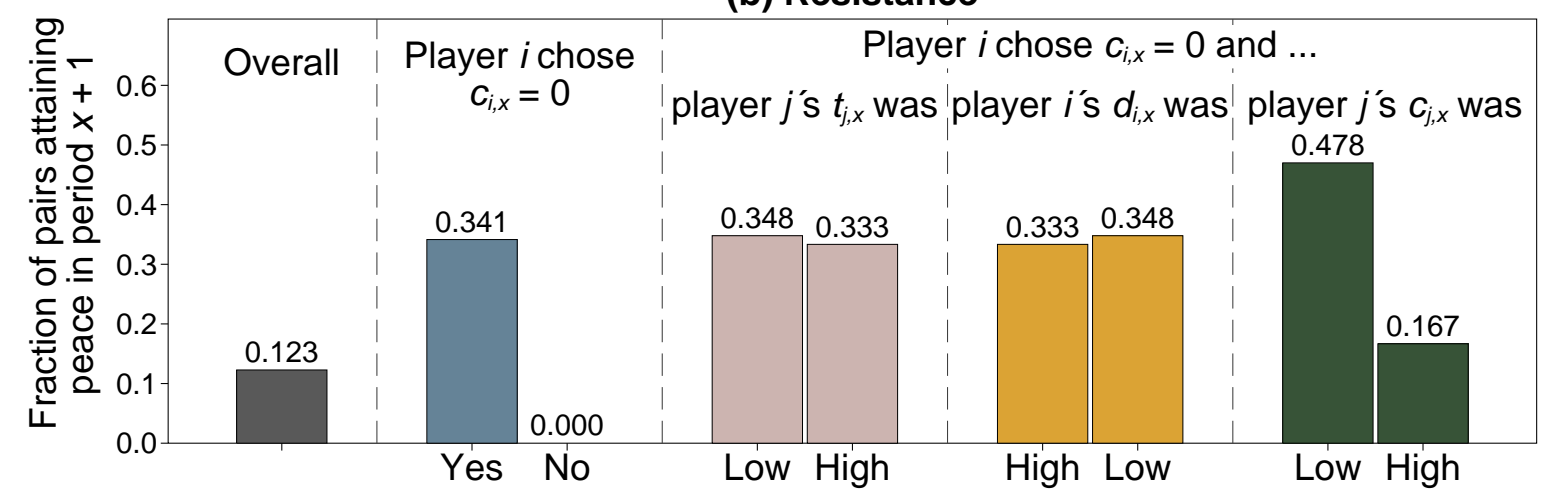

Figure 6: Fraction attaining peace depending on previous period behavior in SE-Partners and RE-Partners

Note: Fractions are calculated based on the first five periods.

like in TC-Partners, peace is attained more often in SE-Partners in periods that follow a low take rate (below the median) compared to periods that follow a high take rate. By contrast, in RE-Partners we do not find that choosing a low take rate facilitates peace. Interestingly, destruction has no effect on the attainment of peace. In both SE-Partners and RE-Partners, the fraction of peaceful relationships is about the same in periods following a high destruction rate (above the median) and in periods following a low destruction rate (below or equal to the median). In other words, punishing winners by destroying income is not an effective way of attaining peace.

To test whether these latter effects are statistically significant, we run a Probit regression for each treatment. ${ }^{28}$ We find that low conflict expenditures by the winner in period $x$ have

\footnotetext{
${ }^{28}$ Probit regressions with the same characteristics as the regression in footnote 18 plus one additional independent variable: a dummy variable indicating whether $j$ 's destruction rate was above the median. We have 36 (41) observations in 17 (22) pairs of subjects in SE-Partners (RE-Partners). The estimated regression equation for SE-Partners is: Probability of peace in $x+1=-1.900(0.490)+1.067(0.570) \times$ Low conflict expenditures
} 
a positive impact on the probability of attaining a peaceful relationship in period $x+1$ in RE-Partners $(p=0.008)$ but not in SE-Partners $(p=0.061)$. Conversely, low take rates significantly increase the probability of peace only in SE-Partners $(p=0.003)$ and not in RE-Partners $(p=0.376)$. Lastly, high destruction rates have no significant effect in either treatment $(p>0.197)$. We summarize these findings as our last result.

Result 4 (Destruction and the De-escalation of Conflict) Giving losers the opportunity to destroy their income does not affect the reduction in conflict expenditures due to repeatedly interacting with the same counterpart. Long-lasting peaceful relationships are attained with equal frequency when losers can destroy their income than when they cannot. It appears that punishment through the destruction of income is not an effective signal of peaceful intentions.

\section{Discussion}

In this section, we discuss potential explanations for the experimental results. So far, we have used as the theoretical benchmark the equilibria obtained by assuming players are risk-neutral and maximize own their earnings. This is a useful benchmark as it gives us clear predictions. However, we see important deviations from this benchmark in both Strangers and Partners treatments. We consider potential explanations for these deviations in turn.

\subsection{Escalation of conflict among strangers}

In the Strangers treatments, we observe three important deviations from the risk-neutral and own-earnings maximization benchmark. First, mean conflict expenditures are above $\frac{1}{2} y$ in TC-Strangers. Second, there are differences in conflict expenditures between TC-Strangers, SE-Strangers, and RE-Strangers that are driven by the willingness of contest losers to destroy their remaining income. Third, conflict expenditures escalate over time in all three games.

We start by considering risk aversion. There is plenty of evidence that individuals display risk-averse behavior in laboratory experiments (e.g., Holt and Laury, 2002). High conflict expenditures in TC-Strangers can be the result of subjects being risk averse (Skaperdas, 1991). ${ }^{29}$

$+1.526(0.520) \times$ Low take rate $+0.539(0.419) \times$ High destruction rate. The estimated regression equation for RE-Partners is: Probability of peace in $x+1=-0.668(0.626)+1.041(0.391) \times$ Low conflict expenditures $-0.466(0.527) \times$ Low take rate $-0.259(0.547) \times$ High destruction rate. Numbers in parenthesis correspond to robust standard errors clustered on sessions.

${ }^{29}$ For example, if we assume all subjects possess the same CRRA utility function $U_{i}\left(\pi_{i}\right)=\pi_{i}^{1-r}(1-r)$, then conflict expenditures in equilibrium equal $c_{i}^{*}=c_{j}^{*}=y(2-r)$ in the TC game. In which case, the observed mean 
The basic intuition is that risk-averse players are relatively more fearful of losing and therefore insure themselves against a loss by investing more in conflict. However, although risk aversion can explain higher conflict expenditures, it does not predict different behavior in the post-contest stages. Therefore, introducing risk aversion does not explain why we observe important differences between the three games. For that, we need an explanation for why contest losers are willing to destroy their income.

Numerous experiments have shown that individuals are willing to destroy their own resources to punish others for unkind or unfair behavior (Camerer, 2003). For this reason, models of social preferences, which were created to explain this behavior, can explain some of the deviations from our theoretical benchmark (for an overview see Fehr and Schmidt, 2006). These models produce two effects on the amount of resources spent on conflict. On one hand, individuals with strong-enough social preferences are willing to cooperate on the peaceful outcome if they are certain-enough that the other player also possesses strong-enough social preferences. On the other hand, when facing an opponent with selfish preferences, a heightened dislike of being in the loser position or a desire to sanction the other's selfish behavior motivates individuals with social preferences to spend more on conflict than individuals with solely selfish preferences. Thus, whether these models predict higher or lower conflict expenditures depends on the fraction of individuals in the population who possess strong-enough social preferences. ${ }^{30}$

For the post-contest behavior, models of social preferences predict that some of the contest losers will destroy their income if they expect or face a high take rate. Therefore, they also predict that, compared to TC-Strangers, winning the contest is less profitable in both SEStrangers (because losers sometimes destroy) and RE-Strangers (because winners must lower their take rates to avoid destruction), which gives players a smaller incentive to spend resources on conflict. ${ }^{31}$

In summary, with the right parameterization, models of social preferences can explain conflict expenditures above $\frac{1}{2} y$, positive destruction rates, and differences in conflict expenditures between the TC game and the SE and RE games. However, current models face two notable challenges to explain our data. We discuss them in turn.

The first challenge for models of social preferences is that they cannot explain the observed investment in TC-Strangers can be explained by a coefficient of relative risk aversion of $r=0.415$. This value for $r$ falls within the range of estimates elicited in other experiments (e.g., Holt and Laury, 2002).

${ }^{30}$ If we use the model of Fehr and Schmidt (1999) and utilize their proposed distribution of types, we find that for TC-Strangers the latter effect dominates resulting in mean conflict expenditures of 0.632y.

${ }^{31}$ The model of Fehr and Schmidt (1999) with their distribution of types predicts mean conflict expenditures of $0.438 y$ in both SE-Strangers and RE-Strangers, compared to 0.632y in TC-Strangers. 
differences in destruction behavior between SE-Strangers and RE-Strangers unless one changes the models' parameters depending on the game. If contest losers in SE-Strangers correctly anticipate the winner's take rate then, for comparable take rates, they should destroy at the same frequency as in RE-Strangers. However, we find that they destroy less. For instance, for take rates in the upper quintile in RE-Strangers (on average 0.875 ), the mean destruction rate is 0.567, which is significantly higher than the mean destruction rate in SE-Strangers (i.e., 0.351), where take rates average 0.929 (GLS regression with subject random effects and standard errors clustered on sessions, $p=0.024$ ). In other words, punishment behavior is different depending on whether one is punishing an action that already took place or an expected action that has not yet occurred. This finding calls for a model that distinguishes these two situations, perhaps by modeling punishment as being driven primarily by immediate emotions such as anger as less so by anticipatory emotions such as fear (for a discussion of the role of emotions, expectations, and punishment, see van Winden, 2007; Reuben and van Winden, 2008; Hopfensitz and Reuben, 2009).

The second challenge for models of social preferences is that they cannot describe the escalation of conflict. Clearly, explanations for changes in conflict expenditures require additional assumptions concerning how subjects adapt their behavior. We can think of two approaches that fit well with models social preferences. The first approach is to assume that subjects have different initial beliefs concerning the behavior of others (e.g., they could have different priors of the fraction of individuals with strong-enough social preferences), and then they gradually update their beliefs and converge to an equilibrium (e.g., Crawford, 1995; Fudenberg and Levine, 1998). However, for this approach to predict an increasing trend in conflict expenditures one must assume that the subjects' initial beliefs are biased such that a majority starts choosing conflict expenditures that are below the equilibrium. The second approach is to assume that changes in behavior are due to changes in the subjects' preferences due to unanticipated emotional reactions (Loewenstein and Schkade, 1999). We are unaware of an existing model that would predict the dynamics observed in our experiment. However, a promising way forward could be to combine a framework like Cox et al. (2007), which formalizes how emotional states determine an individual's social-preferences, and a theory of how emotional states change over time (e.g., van Winden, 2001). ${ }^{32}$ With this approach, increasing conflict expenditures ensue if

\footnotetext{
${ }^{32}$ For example, Hopfensitz and Reuben (2009) show that being punished triggers emotions of anger that can lead to retaliation. If such retaliatory feelings are strong enough in our setting, they could explain why conflict expenditures escalate over time. It is a crucial question, however, whether retaliation is targeted only towards specific individuals (as in Cinyabuguma et al., 2006; Nikiforakis, 2008) or also towards anonymous, perhaps even uninvolved, members of the group (see Dickson, 2007; Hugh-Jones and Leroch, 2012). Given that the
} 
after choices $c_{i}<c_{j}, i$ 's negative emotional reaction induces an increase in conflict expenditures that is stronger than the decrease in conflict expenditures induced by the positive emotions of winner $j$, which triggers a win-stay-lose-shift like reaction. Particularly, in our case, where the fact that the winner chooses to appropriate resources that belong to the loser ought to trigger relatively strong negative emotionsin contrast to an exogenous prize obtained in a standard rent-seeking game - which may fuel affective states over time (Bosman and van Winden, 2002).

Although our experiment is not explicitly designed to test the merits of these two approaches, we think that the regressions in Tables 1 and 2 provide some guidance as to which approach is more consistent with our data. In particular, the fact the in both TC-Strangers and SE-Strangers, winning/losing the contest per se has an effect on conflict expenditures speaks against most belief-updating models (which are unaffected by the realized outcome of the contest), but is easily reconcilable with a model of emotional states.

\subsection{Partners attaining peace}

In Partners treatments, the most important deviation from the risk-neutral and own-earnings maximization benchmark is that average conflict expenditures are below $\frac{1}{2} y$ in all three games because a sizable fraction of the groups manages to coordinate on the peaceful outcome for many consecutive periods. As we explain below, we are unaware of an existing theoretical model that predicts the subjects' behavior. Therefore, we concentrate on discussing two general approaches that we think have the potential to explain our data.

At first glance, it seems straightforward to explain this behavior with a standard reputation model that assumes the existence of two types of players (e.g., self-interested and conditional cooperators who choose $c_{i, 1}=0$ and then play $c_{i, x}=0$ if $c_{j, x-1}=0$ and best responds otherwise) and incomplete information regarding player types (Kreps et al., 1982). With these assumptions, it is straightforward to show that as long as it is believed that there is a large enough fraction of conditional cooperators, there are equilibria in which self-interested players spend zero points on conflict until the final periods of the game. In other words, such a model not only predicts a difference in cooperation rates but also the endgame effect observed in Partner treatments (see Figures 2 and 5). The drawback of such a model is that it predicts peace is no longer possible once positive conflict expenditures have occurred. This prediction is clearly wrong since most groups attain a long-lasting peaceful relationship after experiencing

probability of meeting the same opponent in a subsequent round is around five percent, targeted retaliation is unlikely. However, a treatment played with a perfect stranger matching protocol would be needed to completely rule out targeted retaliation as an explanation. 
one or more periods of positive conflict expenditures.

Therefore, to utilize this kind of reputation model to explain our data, one would have to assume a more complex type (or types) of conditional cooperators. In this sense, our analysis of the behavior that leads to peaceful relationships is informative as it reveals how conditional cooperators behave. We find that peaceful relationships are preceded by subjects choosing low conflict expenditures and above all by one subject spending zero points on conflict (which never maximizes period earnings unless losers always destroy all their income). ${ }^{33}$ In the postcontest stages, we find that peace is preceded by low take rates, but only in TC-Partners and SE-Partners where winners do not immediately benefit from a take rate less than one. By contrast, in RE-Partners, where earnings maximization implies taking little (i.e., because winners expect losers will destroy if they take too much), low takes rates are not conducive to peace. Lastly, we also find that reducing the amount the winner can appropriate through a high destruction rate does not promote peace. In summary, the actions that lead to peaceful relationships are those that entail subjects unambiguously forgoing earnings in a way that benefits their opponent.

A different approach that could potentially explain the subjects' behavior is that of affective ties (e.g., van Dijk and van Winden, 1997; Sally, 2001; van Winden, 2012). In these models, individuals care about the earnings of another player depending on the strength and valence of their affective tie. Moreover, affective ties are strengthened or weakened depending on the positive or negative emotional impulses that players experience as they interact, where an emotional impulse is determined by another player's behavior compared to a reference point. In our games, if a pair of players shares a strong-enough tie then they both will be willing to spend zero points on conflict. Therefore, if one assumes that costly actions benefiting someone else produce a positive emotional impulse in the latter, it is easy to see how these models can explain a substantial part of the observed behavior. In particular, they easily explain why low conflict expenditures and low take rates in TC-Partners and SE-Partners lead to peace while high destruction rates and low take rates in RE-Partners do not.

Note that these two approaches as not mutually exclusive. In fact, we think of them as being complementary. On one hand, reputation models can be used to predict the strategic behavior of players when some individuals possess social preferences, but they generally overlook how

\footnotetext{
${ }^{33}$ The fact that spending zero points of conflict seems to be a necessary trigger for a peaceful relationship might explain why our results differ with those of Durham et al. (1998), who find little difference between Partners and Strangers. It appears that the complete absence of conflict, which was not possible in Durham et al. (1998), works as a more effective and salient signal of peaceful intentions than minimal but positive conflict expenditures.
} 
such preferences depend on the dynamics of play. On the other hand, models of affective ties concentrate on explaining how preferences depend on the players' experienced interaction, but tend to neglect the more complicated strategic considerations introduced by such ties. For this reason, a hybrid model incorporating elements from both approaches might be a fruitful line of future research (van Winden, 2012). ${ }^{34}$

\section{Conclusions}

We investigate the effects of post-conflict behavior and repeated interaction on the allocation of effort between production and appropriation. We find that, in the absence of repeated interaction with the same counterpart, investment in conflict is not only considerably higher than the standard theoretical benchmark (as is frequently observed in rent-seeking experiments) but also escalates over time. Escalation is due to a sharp increase in conflict expenditures by the player with the lower probability of winning without an equivalent decrease in conflict expenditures by the player with the higher probability of winning, which goes to show how easily conflict escalates at the expense of economic efficiency. We also observe important differences in conflict expenditures depending on the post-contest structure of the games. In particular, if given the choice to destroy their remaining resources, many defeated players prefer to do so rather than allow the victor take them away. Given the willingness of losers to destroy, winning becomes less profitable and leads to less investment in conflict. Hence, both winners and losers do better when the power to appropriate is curbed by the threat of destruction (the Resistance game) than when winners can appropriate as much as they like (the Total Conquest game). For this to occur, however, winners need to be able to commit to a moderate appropriation rate and avoid preemptive destruction (the Scorched Earth game).

A notable characteristic of the conflict games in this study is that players can avoid the contest altogether by not investing any resources in conflict. We find this outcome to be particularly important when players repeatedly interact with the same counterpart as a significant number of groups manage to establish long-lasting peaceful relationships, even after

\footnotetext{
${ }^{34}$ For instance, an interesting prediction of a hybrid approach is that, depending on the type of behavior in early periods, repeated interaction can lead to more peaceful relations among some groups and to long-term vendettas among others (such as the ones seen in Abbink and Herrmann, 2009; Bolle et al., 2014). The reason is that a series of selfless acts can build a positive affective tie that deescalates conflict, but at the same time, a series of selfish acts can foster a negative affective tie that escalates it. In turn, if players anticipate these effects, the shadow of potential future vendettas would make peaceful relationships even more likely (Collier and Hoeffler, 2004). It would be interesting for future research to study why behavior differs between pairs in those crucial early periods.
} 
substantial initial conflict. To attain peace, players use costly signals to communicate their willingness to stop fighting. The most important signal is refraining from any investment in conflict, which implies an almost certain loss of the contest. In addition, appropriating little when it unambiguously implies giving up income also serves as a signal for peace. In contrast, using destruction as a punishment device does not promote peaceful relationships.

Our study provides a first step into the analysis of post-conflict behavior and repeated interaction in conflict games. Further work, both theoretical and empirical, is needed to underpin the specific motivations behind the behavior we observe. In this respect, research on the dynamics of the players' expectations and emotional reactions is a promising way forward as both emotions and beliefs play a crucial role in retaliatory behavior (Hopfensitz and Reuben, 2009; Bolle et al., 2014). In addition, variations of the games presented here can be used to study different appropriation and destruction technologies, larger group sizes, cheap-talk communication, resource asymmetry, and additional contest functions.

\section{References}

Abbink, K. (2012). Laboratory experiments on conflict. In Garfinkel, M. R. and Skaperdas, S., editors, The Oxford Handbook of the Economics of Peace and Conflict, pages 532-553. Oxford University Press, New York.

Abbink, K. and Brandts, J. (2009). Political autonomy and independence: Theory and experimental evidence. Working paper, Universitat Autónoma de Barcelona.

Abbink, K. and de Haan, T. (2011). Trust on the brink of armageddon: The first-strike game. Working paper, University of Amsterdam.

Abbink, K. and Herrmann, B. (2009). Pointless vendettas. Discussion paper 09-10, CBESS.

Abbink, K., Masclet, D., and Mirza, D. (2012). Inequality and inter-group conflicts: Experimental evidence. Working paper, Condorcet Center for Political Economy.

Andreoni, J. and Croson, R. (2008). Partners versus strangers: Random rematching in public goods experiments. In Plott, C. R. and Smith, V. L., editors, Handbook of Experimental Economics Results, pages 776-783. North-Holland, Amsterdam.

Bilmes, L. J. and Stiglitz, J. E. (2008). The three trillion dollar war: The true cost of the Iraq conflict. W.W. Norton \& Company, New York.

Blount, S. (1995). When social outcomes aren't fair: The effect of causal attributions on preferences. Organizational Behavior and Human Decision Process, 63(2):131-144.

Bohnet, I., Greig, F., Herrmann, B., and Zeckhauser, R. (2008). Betrayal aversion: Evidence from brazil, china, oman, switzerland, turkey, and the united states. American Economic Review, 98(1):294-310.

Bolle, F., Tan, J. H., and Zizzo, D. J. (2014). Vendettas. American Economic Journal: Microeconomics, forthcoming. 
Bosman, R. and van Winden, F. (2002). Emotional hazard in a power-to-take experiment. The Economic Journal, 112(476):147-169.

Camerer, C. F. (2003). Behavioral Game Theory. Princeton University Press, Princeton.

Carter, J. R. and Anderton, C. H. (2001). An experimental test of a predator-prey model of appropriation. Journal of Economic Behavior \& Organization, 45(1):83-97.

Cason, T. N. and Mui, V.-L. (2014). Coordinating resistance through communication and repeated interaction. The Economic Journal, forthcoming.

Cherry, T. L., Frykblom, P., and Shogren, J. (2002). Hardnose the dictator. American Economic Review, 92(4):1218-1221.

Chowdhury, S. M., Kovenock, D., and Sheremeta, R. M. (2011). An experimental investigation of colonel blotto games. Economic Theory, 52(3):833-861.

Cinyabuguma, M., Page, T., and Putterman, L. (2006). Can second-order punishment deter perverse punishment? Experimental Economics, 9(3):265-279.

Collier, P. and Hoeffler, A. (2004). Greed and grievance in civil war. Oxford Economic Papers, 56(4):563595.

Copnall, J. (2011). Bloody cattle raids set challenge for south sudan. September 2, BBC News.

Cox, J. C., Friedman, D., and Gjerstad, S. (2007). A tractable model of reciprocity and fairness. Games and Economic Behavior, 59(1):17-45.

Crawford, V. P. (1995). Adaptive dynamics in coordination games. Econometrica, 63(1):103-143.

Davidian, M. and Giltinan, D. M. (1995). Nonlinear Models for Repeated Measurement Data. Chapman and Hall, New York.

Dechenaux, E., Kovenock, D., and Sheremeta, R. M. (2012). A survey of experimental research on contests, all-pay auctions and tournaments. Working paper 2154022, SSRN.

Deck, C. and Sheremeta, R. M. (2012). Fight or flight?: Defending against sequential attacks in the game of siege. Journal of Conflict Resolution, 56(6):1069-1088.

Dickson, E. S. (2007). On the (in) effectiveness of collective punishment: An experimental investigation. Working paper, New York University.

Duffy, J. and Kim, M. (2005). Anarchy in the laboratory (and the role of the state). Journal of Economic Behavior \& Organization, 56(3):297-329.

Dunne, J. P. and Uye, M. (2010). Military spending and development. In Tan, A., editor, The Global Arms Trade, pages 293-305. Routledge, London.

Durham, Y., Hirshleifer, J., and Smith, V. L. (1998). Do the rich get richer and the poor poorer? experimental tests of a model of power. American Economic Review, 88(4):970-983.

Falk, A., Fehr, E., and Fischbacher, U. (2008). Testing theories of fairnessintentions matter. Games and Economic Behavior, 62(1):287-303.

Fehr, E. and Schmidt, K. M. (1999). A theory of fairness, competition, and cooperation. The Quarterly Journal of Economics, 114(3):817-868.

Fehr, E. and Schmidt, K. M. (2006). The economics of fairness, reciprocity and altruism-experimental evidence and new theories. In Kolm, S. C. and Ythier, J. M., editors, Handbook on the Economics of 
Giving, Reciprocity and Altruism, pages 615-691. Elsevier, Amsterdam.

Forsythe, R., Horowitz, J. L., Savin, N. E., and Sefton, M. (1994). Fairness in simple bargaining experiments. Games and Economic Behavior, 6(3):347-369.

Fudenberg, D. and Levine, D. (1998). Learning in games. European Economic Review, 42(3-5):631-639.

Garfinkel, M. R. and Skaperdas, S. (2007). Economics of conflict: An overview. In Sandler, T. and Hartley, K., editors, Handbook of Defense Economics, Volume 2, Defense in a Globalized World, pages 649-709. Elsevier, North-Holland, Amsterdam.

Garfinkel, M. R. and Skaperdas, S. (2012). The Oxford Handbook of the Economics of Peace and Conflict. Oxford University Press, New York.

Gehrig, T., Güth, W., Levati, V., Levinsky, R., Ockenfels, A., Uske, T., and Weiland, T. (2007). Buying a pig in a poke: An experimental study of unconditional veto power. Journal of Economic Psychology, 28(6):692-703.

Grossman, H. I. and Kim, M. (1995). Swords or plowshares? a theory of the security of claims to property. Journal of Political Economy, 103(6):1275-1288.

Haavelmo, T. (1954). A Study in the Theory of Economic Evolution. North-Holland Publishing Co, Amsterdam.

Herrmann, B. and Orzen, H. (2008). The appearance of homo rivalis: Social preferences and the nature of rent seeking. Discussion paper no. 200810, CeDEx.

Hess, G. D. (2008). Guns and Butter: The Economic Causes and Consequences of Conflict. MIT Press, Cambridge.

Hirshleifer, J. (1988). The analytics of continuing conflict. Synthese, 76(2):201-233.

Hirshleifer, J. (1991a). The paradox of power. Economics and Politics, 3(3):177-200.

Hirshleifer, J. (1991b). The technology of conflict as an economic activity. American Economic Review, 81(2):130-134.

Holt, C. A. and Laury, S. K. (2002). Risk aversion and incentive effects. American Economic Review, 92(5):1644-1655.

Hopfensitz, A. and Reuben, E. (2009). The importance of emotions for the effectiveness of social punishment. The Economic Journal, 119(540):1534-1559.

Hugh-Jones, D. and Leroch, M. A. (2012). Reciprocity towards groups: A laboratory experiment on the causes. Working paper, University of Warwick.

Ke, C., Konrad, K. A., and Morath, F. (2013). Brothers in arms an experiment on the alliance puzzle. Games and Economic Behavior, 77(1):61-76.

Keynes, J. M. (1920). The Economic Consequences of the Peace. Harcourt Brace, New York.

Kimbrough, E. O. and Sheremeta, R. M. (2013). Side-payments and the costs of conflict. International Journal of Industrial Organization, 31(3):278-286.

Konrad, K. A. (2009). Strategy and Dynamics in Contests. Oxford University Press, New York.

Kovenock, D., Roberson, B., and Sheremeta, R. M. (2010). The attack and defense of weakest-link networks. Working paper no. 3211, CESifo.

Kreps, D. M., Milgrom, P., Roberts, J., and Wilson, R. (1982). Rational cooperation in the finitely 
repeated prisoners' dilemma. Journal of Economic Theory, 27(2):245-252.

Lei, V., Masclet, D., and Vesely, F. (2013). Competition vs. communication: An experimental study on restoring trust. Working paper, University of Wisconsin.

Loewenstein, G. and Schkade, D. (1999). Wouldn't it be nice? predicting future feelings. In Kahneman, D., Diener, E., and Schwarz, N., editors, Well Being: The Foundations of Hedonic Psychology, pages 87-105. Russell Sage Foundation, New York.

McBride, M. and Skaperdas, S. (2009). Conflict, settlement, and the shadow of the future. Working paper no. 2897, CESifo.

Neary, H. M. (1997a). A comparison of rent-seeking models and economic models of conflict. Public Choice, 93(3-4):373-388.

Neary, H. M. (1997b). Equilibrium structure in an economic model of conflict. Economic Inquiry, $35(3): 480-494$.

Nikiforakis, N. (2008). Punishment and counter-punishment in public good games: Can we really govern ourselves? Journal of Public Economics, 92(1-2):91-112.

Nordhaus, W. D. (2002). The economic consequences of a war with iraq. In Kaysen, C., Miller, S. E., Malin, M. B., Nordhaus, W. D., and Steinbruner, J. D., editors, War with Iraq, pages 51-85. American Academy of Arts and Sciences, Cambridge.

Öncüler, A. and Croson, R. (2005). Rent-seeking for a risky rent: A model and experimental investigation. Journal of Theoretical Politics, 17(4):403-429.

Powell, B. and Wilson, B. J. (2008). An experimental investigation of hobbesian jungles. Journal of Economic Behavior \& Organization, 66(3-4):669-686.

Reuben, E. and Tyran, J.-R. (2010). Everyone is a winner: Promoting cooperation through all-can-win intergroup competition. European Journal of Political Economy, 26(1):25-35.

Reuben, E. and van Winden, F. (2008). Social ties and coordination on negative reciprocity: The role of affect. Journal of Public Economics, 92(1-2):34-53.

Sally, D. (2001). On sympathy and games. Journal of Economic Behavior $\mathscr{E} 3$ Organization, 44(1):1-30.

Schweitzer, M. E., Hershey, J. C., and Bradlow, E. T. (2006). Promises and lies: Restoring violated trust. Organizational Behavior and Human Decision Processes, 101(1):1-19.

Sheremeta, R. M., Masters, W. A., and Cason, T. N. (2012). Winner-take-all and proportional-prize contests: Theory and experimental results. Working paper 12-04, Chapman University.

Skaperdas, S. (1991). Conflict and attitudes toward risk. American Economic Review, 81(2):116-120.

Skaperdas, S. (1992). Cooperation, conflict, and power in the absence of property rights. American Economic Review, 82(4):720-739.

Sköns, E. (2006). The costs of armed conflict. In Peace and Security, pages 169-190. International Task Force on Global Public Goods, Stockholm.

Smith, A., Houser, D., Leeson, P., and Ostadhossein, R. (2011). The costs of conflict. Working paper 1921484, SSRN.

Tingley, D. H. and Walter, B. F. (2011). Can cheap talk deter?: An experimental analysis. Journal of Conflict Resolution, 55(6):996-1020. 
Tullock, G. (1980). Efficient rent seeking. In Buchanan, J. M., Tollison, R. D., and Tullock, G., editors, In Toward a Theory of the Rent Seeking Society, pages 97-112. Texas A\&M University Press, College Station.

van Dijk, F. and van Winden, F. (1997). Dynamics of social ties and local public good provision. Journal of Public Economics, 64(3):323-341.

Van Huyck, J., Battalio, R., Mathur, S., Van Huyck, P., and Ortmann, A. (1995). On the origin of convention: Evidence from symmetric bargaining games. International Journal of Game Theory, $24(2): 187-212$.

van Winden, F. (2001). Emotional hazard exemplified by taxation-induced anger. Kyklos, 54(2-3):491506.

van Winden, F. (2007). Affect and fairness in economics. Social Justice Research, 20(1):35-52.

van Winden, F. (2012). Affective social ties - missing link in governance theory. Rationality, Markets and Morals, 3(57):108-122.

\section{A Descriptive statistics}

Table A1 displays descriptive statistics for all treatments. Table A2 presents the same statistics for peaceful and aggressive groups in the Partner treatments.

Table A1: Means and standard deviations for all treatments

Note: Conflict expenditures and earnings are shown as a fraction of the endowment. The fraction of times subjects choose to spend zero points on conflict is labeled as "peaceful attempts" and the fraction of periods in which the contest is avoided because both subjects in a pair choose to spend zero points on conflict is labeled as "peaceful periods".

\begin{tabular}{|c|c|c|c|c|c|c|}
\hline Variable & $\begin{array}{c}\text { TC- } \\
\text { Strangers }\end{array}$ & $\begin{array}{c}\text { SE- } \\
\text { Strangers }\end{array}$ & $\begin{array}{c}\text { RE- } \\
\text { Strangers }\end{array}$ & $\begin{array}{c}\text { TC- } \\
\text { Partners }\end{array}$ & $\begin{array}{c}\text { SE- } \\
\text { Partners }\end{array}$ & $\begin{array}{c}\text { RE- } \\
\text { Partners }\end{array}$ \\
\hline \multirow[t]{2}{*}{ Conflict expenditures } & 0.631 & 0.573 & 0.456 & 0.381 & 0.371 & 0.278 \\
\hline & $(0.262)$ & $(0.252)$ & $(0.243)$ & $(0.351)$ & $(0.336)$ & $(0.318)$ \\
\hline \multirow[t]{2}{*}{ Peaceful attempts } & 0.038 & 0.058 & 0.035 & 0.339 & 0.350 & 0.424 \\
\hline & $(0.192)$ & $(0.234)$ & $(0.184)$ & $(0.474)$ & $(0.477)$ & $(0.495)$ \\
\hline \multirow[t]{2}{*}{ Peaceful periods } & 0.003 & 0.006 & 0.000 & 0.263 & 0.275 & 0.318 \\
\hline & $(0.051)$ & $(0.079)$ & $(-)$ & $(0.441)$ & $(0.447)$ & $(0.466)$ \\
\hline \multirow[t]{2}{*}{ Take rate } & 0.981 & 0.929 & 0.645 & 0.811 & 0.781 & 0.573 \\
\hline & $(0.098)$ & $(0.017)$ & $(0.179)$ & $(0.289)$ & $(0.250)$ & $(0.203)$ \\
\hline \multirow[t]{2}{*}{ Destruction rate } & & 0.351 & 0.249 & & 0.407 & 0.283 \\
\hline & & $(0.447)$ & $(0.416)$ & & $(0.461)$ & $(0.437)$ \\
\hline \multirow[t]{2}{*}{ Earnings } & 0.369 & 0.338 & 0.467 & 0.619 & 0.542 & 0.645 \\
\hline & $(0.442)$ & $(0.412)$ & $(0.372)$ & $(0.483)$ & $(0.171)$ & $(0.388)$ \\
\hline
\end{tabular}


Table A2: Means and standard deviations for peaceful and aggressive groups

Note: Data solely from Partners treatments. Conflict expenditures and earnings are shown as a fraction of the endowment. The fraction of times subjects choose to spend zero points on conflict is labeled as "peaceful attempts" and the fraction of periods in which the contest is avoided because both subjects in a pair choose to spend zero points on conflict is labeled as "peaceful periods".

\begin{tabular}{lcccccc}
\hline \hline \multirow{2}{*}{ Variable } & \multicolumn{3}{c}{ Peaceful groups } & \multicolumn{3}{c}{ Aggressive groups } \\
& $\mathrm{TC}$ & $\mathrm{SE}$ & $\mathrm{RE}$ & $\mathrm{TC}$ & $\mathrm{SE}$ & $\mathrm{RE}$ \\
\hline Conflict expenditures & 0.065 & 0.065 & 0.059 & 0.545 & 0.510 & 0.440 \\
& $(0.193)$ & $(0.199)$ & $(0.163)$ & $(0.298)$ & $(0.292)$ & $(0.308)$ \\
Peaceful attempts & 0.838 & 0.850 & 0.804 & 0.080 & 0.123 & 0.145 \\
& $(0.369)$ & $(0.358)$ & $(0.398)$ & $(0.272)$ & $(0.328)$ & $(0.352)$ \\
Peaceful periods & 0.769 & 0.770 & 0.700 & 0.000 & 0.050 & 0.037 \\
& $(0.422)$ & $(0.422)$ & $(0.459)$ & $(-)$ & $(0.218)$ & $(0.189)$ \\
Take rate & 0.698 & 0.630 & 0.581 & 0.825 & 0.791 & 0.571 \\
& $(0.374)$ & $(0.377)$ & $(0.330)$ & $(0.274)$ & $(0.237)$ & $(0.160)$ \\
Destruction rate & & 0.545 & 0.457 & & 0.392 & 0.243 \\
& & $(0.510)$ & $(0.480)$ & & $(0.454)$ & $(0.418)$ \\
Earnings & 0.935 & 0.876 & 0.876 & 0.455 & 0.390 & 0.475 \\
& $(0.306)$ & $(0.329)$ & $(0.318)$ & $(0.478)$ & $(0.428)$ & $(0.345)$ \\
\hline \hline
\end{tabular}

